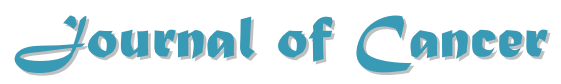

$2011 ; 2: 1-19$

Review

(C) Ivyspring International Publisher. All rights reserved

\title{
Prognostic Factors for Failure aiter Prostatectomy
}

\author{
Gregory P. Swanson ${ }^{1 凶}$ and Joseph W. Basler ${ }^{2}$ \\ 1. Departments of Radiation Oncology, Radiology and Urology, UT Health Science Center San Antonio, San Antonio, TX \\ 78229, USA. \\ 2. Department of Urology, UT Health Science Center San Antonio, San Antonio, TX 78229, USA.
}

$\triangle$ Corresponding author: Gregory P. Swanson, MD, Associate Professor of Radiation Oncology, The University of Texas Health Science Center at San Antonio, 7703 Floyd Curl Drive MC7889, San Antonio, TX 78229, USA. Tel: 210-450-1109; Fax: 210-450-5085; Email: swansong@uthscsa.edu

Received: 2010.10.19; Accepted: 2010.12.06; Published: 2010.12.07

\begin{abstract}
Several randomized studies have been completed in prostate cancer that show a benefit to immediate postoperative treatment in patients undergoing prostatectomy. In one of the studies, there was even a survival advantage. In spite of those positive findings, there has been some reluctance to uniformly offer adjuvant treatment to patients. The perception is that the risk is not really high enough to warrant the risk of toxicity that comes with treatment. There are clearly factors that can help predict who is at the highest risk. Our purpose is to review those factors and identify patients that have a high enough risk justifying immediate treatment.
\end{abstract}

Key words: adjuvant radiation, adjuvant therapy, high risk, Prostate cancer, prostatectomy

\section{Introduction}

The use of post surgical adjuvant treatment in oncology is common. In virtually every disease site, patients are routinely offered post operative chemotherapy, hormonal therapy and/or radiation therapy. In many cases, their use is well defined by multiple clinical trials. While trials have been performed in prostate cancer (primarily with the use of adjuvant radiation therapy)(1-3), there is still much controversy as to the routine use of adjuvant therapy after prostatectomy.

The whole purpose of adjuvant treatment is to reduce the risk of morbidity and mortality that would come with cancer recurrence. Prostate cancer is unique from most other cancers in two ways. First, it has a long natural history. In general, it progresses more slowly than most other cancers. There is serious discussion about whether many prostate cancers need to be treated at all, the premise being that patients will die of other causes before the prostate cancer ever becomes life threatening (4). The second factor is that prostate cancer has a fairly reliable marker in Prostate Specific Antigen (PSA). This is truly unique in all of oncology. In almost every case, the PSA will rise long before clinical evidence of recurrence becomes manifest (i.e. prostate fossa nodule or radiographically detectable nodal or bone metastasis). With this marker, there are many that feel that adjuvant treatment can be deferred until the PSA becomes elevated (5) (at which time it becomes salvage treatment). This is pure supposition as there are no studies directly comparing adjuvant versus salvage treatment, but the thinking (and the hope) is that PSA is sensitive enough that waiting for its rise will not decrease any survival benefit of intervention. While there is also controversy (6) about whether a rising PSA is truly a surrogate for clinical failure with metastasis (which uniformly leads to death), one thing is certain- virtually no one dies of prostate cancer without a rising PSA. So, no matter how you look at it, a rising PSA is not a good thing if you have had your prostate removed for cancer. Also, 
patients have already made a difficult decision to proceed with a major procedure with the premise they will be cured of cancer. For most patients, a rising PSA post prostatectomy is a major psychological blow. (7)

Our ultimate goal is to reduce the death rate of prostate cancer. Some of the ambivalence about the use of adjuvant treatment is that in patients that undergo curative surgery, the impression is that very few ultimately die of prostate cancer and the risk is somewhat mitigated by the use of salvage radiation therapy and androgen ablation. Therefore the argument is made that we should not routinely subject most patients to adjuvant treatment as it is not likely to have a major impact on survival and we will have subjected too many men to needless damaging treatment. (5) Still, it is a failure of us as physicians if someone dies from something we could have prevented, especially after having failed to follow a major surgical intervention with curative adjuvant treatment (curatio interruptus). The fact remains that more than 27,000 men (8) die from prostate cancer each year and they are coming from somewhere. Since there are not many patients that present with metastatic disease $(\sim 4 \%)(9)$, almost all of the current prostate cancer deaths are in men that fail with metastatic disease after primary intervention. Therefore more than 25,000 men will subsequently be found to have metastatic disease and die, about half of which will have undergone surgery (9). If we could identify those patients, it would make the decision about adjuvant treatment relatively easy.

At the same time, if we had effective, inexpensive adjuvant therapy that had no or minimal morbidity, it would also make for an easier decision. Of course, neither of those conditions exists, so it really comes down to compromises and trade offs in the terms of risk and benefits. The remainder of this discussion is to how we identify patients with enough risk that we should seriously consider adjuvant treatment. If we can identify those patients, it is only half the discussion with the remaining consideration being the efficacy and toxicity of the adjuvant treatment.

\section{PSA as a predictor of mortality}

There are some things we do know. The cause of death from prostate cancer is from metastatic disease and metastatic disease is not curable. We can delay the inevitable death with androgen ablation (10)( for about 2 years) and with chemotherapy (11) (for about 1 month), but unless the patients are "lucky" enough to die from something else in the interim, they will ultimately die from the cancer. Once metastatic dis- ease develops, the race is on, and there is no winner. Therefore, the development of metastatic disease is a fair endpoint in the evaluation of prostate cancer mortality and the prevention of metastasis is a reasonable goal.

It is also a fact that no one (virtually) develops metastatic disease dies of prostate cancer without an elevated PSA. As a result, there is a real temptation to use PSA as a surrogate for prostate cancer outcome. This is made more compelling by the fact that it is universally obtained in patients post prostatectomy and it is a hard number- it is not quite as subjective as trying to interpret a bone or CT scan. Also, patients are tuned into the implications of a rising PSA, so it is very difficult to dismiss it after the fact. Of course, the dilemma is that there can be a long interval between a rising PSA and metastasis/death. In the famous Hopkins study (12), in a subgroup of patients that weren't offered treatment at the time of initial PSA rise, it took a median of 8 years (37\% at 5 years) for metastatic disease to manifest itself and a median of 5 years for them to die. Presumably, they received androgen ablation at the time of metastatic disease. It is worth noting that every patients with metastatic disease died of prostate cancer, so if the PSA failure was prevented (if it was possible), they would not have died of cancer. Also, even though not everyone developed metastatic disease at the time of analysis, the metastasis free survival curve has an unwavering downward slope that if it continues as is; every patient will have metastatic disease or be dead by 20 years. Of course, not everyone will die of cancer as long as they die of something else first, and, in an aging population, it is a real possibility. It is this group that complicates the situation as we do not want to offer potentially morbid treatment to men that don't really need it. There is no good solution for this dilemma. In their study, the Hopkins researchers tried to identify factors unique to the patients developing metastatic disease sooner than later. They found that Gleason score, the time from surgery to recurrence and PSA doubling time predict for earlier metastatic disease. Unfortunately, if you wait for the PSA to declare itself, you are already behind the curve when it comes to intervention, especially in what is obviously a more virulent cancer. Dilemmas aside, one fact remains: in spite of the long natural history, the study does show us that in men with a rising post prostatectomy PSA ultimately all of them will develop metastatic disease, $70 \%$ of them by 10 years and that disease will be fatal. There is no denying that post prostatectomy rising PSA is an enormously powerful predictor of metastatic disease. Therefore, in using the risk of PSA failure as an indicator of patients that are 
at also at a high risk for metastasis and death is not unreasonable. The highest risk patients are those that have a high incidence of biochemical failure and do so in the first couple of years.

\section{Risk warranting intervention}

In identifying patients at high risk for failure, PSA is not only a marker of recurrence, but is also one of the three most widely accepted prognostic markers for recurrence in prostate cancer. The other two are grade (usually in the form of Gleason score) and stage (with pathological stage being more accurate than clinical stage). As noted above, PSA is the least subjective. Although there is lab variation, there is consistency and a number is more definite. Regarding grade, before the 1980's, as with most cancers, nuclear grade was how prostate cancer was graded. This has now been supplanted by the Gleason scoring system which encompasses not only the features of grade, but the morphology of the cancer. It has become ubiquitous in urologic oncology to the point where it is usually the only grade reported. It is subjective as it requires the pathologist to score the appearance of the cancer. The concordance between those specializing in urologic pathology is no better than $70 \%$. (13) Also, the Gleason score of the prostate biopsy is only a relative representation of that in the final pathologic specimen from the prostatectomy. Exact correlation between the biopsy and prostatectomy Gleason score occurs only about $50 \%$ of the time (14) and clearly the larger volume of tissue in a prostatectomy specimen allows for a more definitive determination. Staging is also greatly improved by being able to evaluate the prostatectomy specimen. Although there is some correlation between clinical stage and outcome, clinical staging is fairly subjective. Although subject to the variations of methodology, pathologic staging, (especially the details about margins), seminal vesicle involvement and lymph node involvement, provides a lot more specific information and is much more preferred in risk analysis than clinical staging. While each of the prognostic triad is independently predictive of outcome, as we will discuss later the three together are much more powerful than any one of them individually.

As discussed above, the Hopkins data would indicate that patients with a post prostatectomy rising PSA if left untreated have a metastasis rate of $70 \%$ by 10 years.(12) This is supported by the data from the SWOG study where for the observation group (noting that $>30 \%$ subsequently received radiation and/or androgen ablation), 56\% suffered biochemical failure by 5 years, which translated into a metastasis free survival of $60 \%$ at 10 years and $40 \%$ at 15 years. Ac- counting for the salvage treatment in the SWOG group, this is remarkably similar to the Hopkins data (which excluded patients receiving salvage therapy that had a durable response). Further, in the SWOG study, the overall survival difference between the observation group and the immediate adjuvant radiation therapy group was $8 \%$ at 10 years and $11 \%$ at 15 years. (1) Cause specific survival was not delineated, but it would appear that this $\sim 10 \%$ difference in survival was due to uncontrolled cancer. That would mean that the $56 \% 5$ year biochemical failure rate in the observation patients not only translates into at least a $17 \%$ metastasis rate (15), but also $~ 10 \%$ cancer death rate by 10 years. This is conservative given that the radiation did not cure everyone in the comparative group (for example, the metastasis incidence dropped for $17 \%$ to $8 \%$ with radiation, not to 0 ). Further evidence comes from another study with 265 prostatectomy patients that suffered a biochemical recurrence and $17 \%$ of them died of cancer with a median follow up of 10 years, even with salvage treatments. (16). As would be expected, none of the 448 patients without biochemical failure died of cancer. One pathologic subgroup had a $63 \%$ PSA failure rate, suffering a $10 \%$ death rate from cancer and another group had an $88 \%$ biochemical failure rate resulting in a $34 \%$ cancer death rate. The exact same prostate cancer death incidence $(17 \%)$ was reported in a study of 379 men with biochemical failure after prostatectomy (17). Taken together, these different studies would indicate that patients with a 50-60\% biochemical failure rate have at least a $10 \%$ risk of dying of prostate cancer and the higher the risk of biochemical failure, the higher the risk of cancer death. So, we would argue that the place to seriously consider adjuvant treatment is in patients that have a biochemical failure rate of greater than $50-60 \%$. This is actually conservative. In clinical trial design, some have designated patients as high risk of recurrence (warranting neoadjuvant chemotherapy) if the nomogram predicted risk of failure was $>40 \%$ by 5 years (18). Others have proposed that patients with a biochemical failure rate of $25-35 \%$ are appropriate candidates for adjuvant local therapy (19). Given that, we would argue that our threshold is reasonable and that patients with $<50 \% 5$ year biochemical control have a high enough risk of metastasis and death to warrant serious consideration of adjuvant treatment.

\section{Seminal vesicle and lymph node positive}

The determination of risk is not straightforward. As discussed earlier, the three standard prognostic factors are Gleason score, PSA and stage. There are subgroups in each that appear to have a very high risk 
of recurrence. So the first place to start is whether there are any single factors that portend such a great risk that they alone would indicate the need for adjuvant treatment. One that easily falls into this category is that of positive lymph node metastasis. The risk of failure in these patients is non-controversial and we won't discuss it further. We would submit that the second of these is that of seminal vesicle involvement, which has been extensively studied (Table $1)$.

Table I. Effect of seminal vesicle involvement on failure

\begin{tabular}{|c|c|c|c|c|c|c|c|c|c|c|}
\hline \multirow{2}{*}{$\begin{array}{l}\text { SV } \\
\text { Study }\end{array}$} & \multirow[b]{2}{*}{$\#$ pts } & \multirow[b]{2}{*}{$\begin{array}{l}\text { PSA } \\
\text { Failure }\end{array}$} & \multirow[b]{2}{*}{$\begin{array}{l}\text { Months } \\
\text { Med f/u } \\
\text { (mean) }\end{array}$} & \multirow{2}{*}{\multicolumn{2}{|c|}{ modifiers }} & \multirow{2}{*}{\multicolumn{2}{|c|}{ Failure rate }} & \multirow[b]{2}{*}{5 yr DFS } & \multirow[b]{2}{*}{7 yr DFS } & \multirow[b]{2}{*}{10 yr DFS } \\
\hline & & & & & & & & & & \\
\hline \multirow{3}{*}{ Swanson ${ }^{16}$} & 35 & \multirow[t]{3}{*}{$>0.3$} & \multirow[t]{3}{*}{121} & \multirow{3}{*}{\multicolumn{2}{|c|}{$\begin{array}{l}\text { EPE- mar- } \\
\text { EPE+mar- } \\
\text { EPE+mar+ }\end{array}$}} & \multicolumn{2}{|l|}{$60 \%$} & $47 \%$ & & $33 \%$ \\
\hline & 9 & & & & & $75 \%$ & & $33 \%$ & & $17 \%$ \\
\hline & 19 & & & & & $95 \%$ & & $10 \%$ & & $0 \%$ \\
\hline $\operatorname{Han}^{22}$ & 113 & $>0.2$ & 76 & & & & & $48 \%$ & $30 \%$ & $17 \%$ \\
\hline Roehl $^{24}$ & NS & $\geq 0.3$ & (65) & & & & & & & $26 \%$ \\
\hline Trapasso $^{27}$ & 93 & $>0.4$ & 34 & & & & & $40 \%$ & & \\
\hline \multirow[t]{6}{*}{ Sofer 29} & 10 & \multirow[t]{6}{*}{$>0.3$} & \multirow[t]{6}{*}{43} & \multicolumn{2}{|l|}{ Gl 2-6 } & \multicolumn{2}{|l|}{$40 \%$} & & & \\
\hline & 30 & & & \multicolumn{2}{|l|}{ Gl 7} & \multicolumn{2}{|l|}{$47 \%$} & & & \\
\hline & 26 & & & \multicolumn{2}{|c|}{ Gl 8-10 } & \multicolumn{2}{|l|}{$58 \%$} & & & \\
\hline & 18 & & & \multicolumn{2}{|c|}{ Cap pen } & $67 \%$ & & & & \\
\hline & 41 & & & EPE & & $49 \%$ & & & & \\
\hline & 34 & & & Mar+ & & $56 \%$ & & & & \\
\hline Stephenson ${ }^{30}$ & 195 & $\geq 0.2 \times 2$ & 38 & Mar+ & & & & & $21 \%$ & \\
\hline & 224 & & & Mar- & & & & & $48 \%$ & \\
\hline Karakiewicz $^{31}$ & 352 & $0.1-0.4$ & 25 & Mar- & & & & $43 \%$ & & $20 \%$ \\
\hline & 300 & & & Mar+ & & & & $19 \%$ & & $12 \%$ \\
\hline Hull 32 & 81 & 0.4 & 47 & & & & & $37 \%$ & & $37 \%$ \\
\hline Salomon ${ }^{33}$ & 137 & $>0.2$ & (59) & & & $52 \%$ & & $34 \%$ & & $10 \%$ \\
\hline & & & & & & PSA* & & & & \\
\hline & & & & & & $0-4$ & $20-50$ & & & \\
\hline $\mathrm{D}^{\prime}$ Amico ${ }^{34}$ & 70 & $>0.1$ & $42^{*}$ & Gl & Mar- & $66 \%$ & $96 \%$ & & & \\
\hline & NS & & & $8-10$ & Mar + & $89 \%$ & $99 \%$ & & & \\
\hline & & & & Gl & mar- & $55 \%$ & $91 \%$ & & & \\
\hline & & & & 7 & Mar+ & $79 \%$ & $99 \%$ & & & \\
\hline & & & & Gl & mar- & $51 \%$ & $88 \%$ & & & \\
\hline & & & & $5-6$ & Mar+ & $76 \%$ & $99 \%$ & & & \\
\hline & & & & Gl & mar- & $36 \%$ & $74 \%$ & & & \\
\hline & & & & $2-4$ & Mar+ & $59 \%$ & $93 \%$ & & & \\
\hline Quinn ${ }^{35}$ & 79 & $>0.4$ & $39(41)$ & & & $30 \%$ & & & & \\
\hline Tefilli ${ }^{36}$ & 59 & $>0.4$ & 43 & Mar+ & & & & $14 \%$ & & \\
\hline & 34 & & & Mar- & & & & $49 \%$ & & \\
\hline & 70 & & & $\mathrm{PSA}<1$ & & & & $59 \%$ & & \\
\hline & 23 & & & PSA $>1$ & & & & $17 \%$ & & \\
\hline & 8 & & & $\mathrm{Gl}<7$ & & & & $45 \%$ & & \\
\hline & 85 & & & $\mathrm{Gl}>7$ & & & & $22 \%$ & & \\
\hline Freedland 37 & 135 & $\geq 0.2 \times 2$ & 32 & & & & & $36 \%$ & & \\
\hline & 80 & & & Mar + & & & & $21 \%$ & & \\
\hline & 55 & & & Mar - & & & & $56 \%$ & & \\
\hline
\end{tabular}

Definition of failure and disease free survival: based on biochemical (PSA) failure and includes biopsy proven local recurrence and radiologically detected distant metastasis

* 2 year endpoint for all groups. Mar+ is margin positive; Mar- is margin negative; EPE+ is extraprostatic extension present; EPE- is extraprostatic extension absent; foc is focal; Ext is extensive; Est is established; Gl is Gleason score

There were several concurrent reports from John Hopkins that included seminal vesicle positive patients $(\mathrm{SV}+)$ with differing follow up and selection criteria. In an early study, (20) there was no difference in failure between $\mathrm{SV}+$ and $\mathrm{LN}+$ patients and they were grouped together with the finding of a 5 and 10 year failure free survival of $37 \%$ (63\% failure rate) and
$13 \%$, respectively. In a larger study from the same year (21), 2091 patients were followed for a median of 5.9 years. On multivariate analysis, Gleason score, preoperative PSA and whether organ confined (versus extraprostatic or lymph node positive) were significant factors for recurrence. Among factors that were not predictive were margin status and seminal 
vesicle involvement. In this cohort, it appears that extraprostatic extension (EPE) alone was a strong enough predictor that no additional prognostic information was realized from the seminal vesicle status. In yet another large study from the same institution (22) with a slightly longer mean follow up of 6.3 years, $17 \%$ of the patients had failed (PSA >0.2). For the SV+ patients, 5 year disease free survival was $48 \%$, dropping to $30 \%$ by 10 years and $17 \%$ by 15 years. (Table 1). Finally, in a more recent version, (23) seminal vesicle positive patients had a $75 \%$ biochemical failure rate and $23 \%$ death rate by 12 years. From all these studies, it appears that although seminal vesicle involvement is not always a driving predictive factor (as evidenced by the multivariate analysis in the middle study), it is clear that their SV positive patients have a very high risk of failure.

Obviously, failure risk will be determined by length of follow up. In a study with relatively long follow up (65 months) (24), even though some of the patients received adjuvant radiation therapy, for SV positive patients, the 10 year disease free survival rate was $26 \%$. (Table 1). In an earlier more detailed description (25) of some of the same patients, considering the factors of grade, PSA and pathological stage, the most favorable patients with positive seminal vesicles had a PSA $<10 \mathrm{ng} / \mathrm{ml}$ and well differentiated tumors resulting in a 7 year disease free survival of $61 \%$. For those with moderately differentiated cancer, it dropped to $46 \%$ and for the poorly differentiated $33 \%$. If the PSA was $>10 \mathrm{ng} / \mathrm{ml}$, all three groups did much worse $(25 \%, 11 \%$, and $5 \%$, respectively). In a study with even longer follow up (121 months) lymph node positive patients were excluded (16) and $37 \%$ of the entire cohort recurred (PSA $>0.3$ ). For SV positive patients, overall $73 \%$ failed and $28 \%$ died of cancer, which increased to $88 \%$ and $34 \%$ if they also had extraprostatic disease (EPE).

Numerous studies have reported 5 year control rates in the $40-60 \%$ range for SV positive patients, influenced by length of follow up, use of adjuvant treatment and other defining factors; $52 \%$ (26), $40 \%$ (27), and 36\% (Gleason 8-10)(28). Several studies simply described the failure rate. In one (29) with 106 SV positive patients, with a median follow up of 43 months, for Gleason 2-6, 40\% failed; Gleason 7, 47\%; and Gleason 8-10, 58\%. Another (19) found that Gleason 8-10 and SV+ patients had a very high 7 year failure rate $(72 \%)$, which was slightly improved if the PSA was $\leq 10 \mathrm{ng} / \mathrm{ml}(63 \%)$ versus $>10 \mathrm{ng} / \mathrm{ml}(86 \%)$.

There have been two large pooled studies of radical prostatectomy patients. Unfortunately, the follow up is relatively short and many patients were excluded for various reasons. In the first (30) with 3 institutions, 419 seminal vesicle positive patients were identified with a median follow up of 38 months. Those that had negative margins had a $48 \% 5$ year disease free survival and for margin positive, $21 \%$. The other large pooled analysis (31) resulted in $352 \mathrm{SV}$ positive patients, but with a median follow up of only 25 months. On multivariate analysis, significant factors for recurrence were PSA, Gleason score, margin status, EPE, and SV involvement. SV positive patients with positive margins had a 5 and 10 year failure free survival of only $19 \%$ and $12 \%$ respectively and for negative margins $43 \%$ and $20 \%$, respectively. One of the participating institutions (32) reported on their own cohort, but with longer follow up (median 47 months). Fifteen percent of the patients failed (PSA 0.4 $\mathrm{ng} / \mathrm{ml}$ ) for a 10 year failure free survival of $75 \%$. As with the multi-institutional study, on multivariate analysis, Gleason score, EPE, margin status and SV status were predictive. For SV positive patients, 5 and 10 year disease free survival were both $37 \%$. The 10 year metastasis free survival was $57 \%$. In a smaller combined study (33), 137 SV positive patients were followed for a median of 4.9 years. Fifty two percent failed (PSA $>0.2 \mathrm{ng} / \mathrm{ml}$ ) resulting in a 10 year progression free survival of $10 \%$. On multivariate analysis, PSA and Gleason were predictive of failure, but $\mathrm{EPE}$ and margin status were not. A more aggressive approach (34) to patient selection was to look at the 2 year failure rate with supposition they would be more likely to develop metastatic disease. With that supposition, it was proposed that a 2 year failure rate of $>50 \%$ was certainly enough to warrant adjuvant intervention. Almost all the SV positive patients fell into that category. It might be possible to tease out patients that don't need treatment, but in this study, the lowest risk patients (PSA $<4 \mathrm{ng} / \mathrm{ml}$, Gleason 2-6 and margin negative) still had a 2 year failure rate of $36 \%$.

As noted from Table 1, the failure rate for SV positive cancer is high, although there are series where it is not so dire (35). Undoubtedly, these variations are from the presence of other mitigating factors. As noted in some of the studies cited above, some factors might be able to better define who will fail. In a study (36) of 93 SV positive patients, 57\% recurred. Five year disease free survival was $17 \%$ for PSA $>10$ $\mathrm{ng} / \mathrm{ml}, 22 \%$ for Gleason $>7$ and $14 \%$ for margin positive patients, compared to $59 \%$ for PSA $<10 \mathrm{ng} / \mathrm{ml}$, $45 \%$ for Gleason $<7$ and $49 \%$ for negative margin. In a similar study (37) of $135 \mathrm{SV}$ positive patients, 5 year progression free survival was $36 \%$. If the margins were positive, it dropped to $21 \%$, but if negative, slightly better at $56 \%$. In 19 patients that had Gleason 2-6 cancer with negative margins, the 5 year disease free survival was $69 \%$, which was similar to the SV 
negative patients. For the 11 patients in that group less than 60 years of age, there were no failures. Finally, (38) the lowest risk was for patients with Gleason $<7$ and PSA $<10 \mathrm{ng} / \mathrm{ml}$, with a $75 \% 34$ month disease free survival. For Gleason 7 patients it was only $54 \%$. These studies suggest that it might be possible to try to select out patients that may not have as high a risk of failure. One more complex attempt to do this was using Gleason score and the percentage of biopsy cores as a discriminator (39) A 2 year failure rate was chosen as previous observations indicated that patients failing in the first two years were highly likely $(>50 \%)$ to develop metastatic disease by five years. For SV positive Gleason 8-10 patients all the patients (any PSA, any margin status) had at a 2 year failure risk of at least $50 \%$ except for patients with both PSA $<20 \mathrm{ng} / \mathrm{ml}$. and $<34 \%$ biopsy positivity. All the SV positive Gleason 7 patients had $>50 \% 2$ year failure rate except those with PSA $<20 \mathrm{ng} / \mathrm{ml}$ and margins negative and $<34 \%$ positive cores. The patients in that group (Gleason 7, margin negative) with $34-50 \%$ positive cores had a 2 year recurrence rate of $40-47 \%$. The great caution here is that although the exact patient numbers for each of the subgroups was not reported, with this many subgroups, it invariability got very small, likely down to $1-2$ patients. This would be especially true in the lower grade patients as low Gleason scores are uncommon in seminal vesicle positive patients. So, for the Gleason 2-6 patients with PSA less than $10 \mathrm{ng} / \mathrm{ml}$. , while there was no subgroup with a greater than $45 \% 2$ year failure, great care should be taken before using this data as a reason not to treat. Of course, these cautions are true for most retrospective data, especially those that divide the data down to very small specific subgroups. The bulk of the data would indicate that seminal vesicle positive patients have a significant risk of failure and that adjuvant therapy is warranted.

The limitations of the small numbers of patients in the more favorable subgroups make selecting those patients for avoidance of intervention a risky proposition. In a subgroup analysis of the SWOG adjuvant study (also with small numbers), all the subgroups benefitted from adjuvant radiation to the same degree (40).

\section{Gleason score}

Gleason score is also highly prognostic. Patients are usually grouped by Gleason score $<7 \mathrm{ng} / \mathrm{ml}$ (low risk), $7 \mathrm{ng} / \mathrm{ml}$ (intermediate risk) and $>7 \mathrm{ng} / \mathrm{ml}$ (high risk). Gleason 7 is frequently combined with Gleason 8-10 when the findings indicate a comparable risk $(16,41)$ While the findings for Gleason 7 is somewhat variable, there is little question that Gleason 8-10 pa- tients have a high risk of failure. This dates back to some of the earliest prostatectomy series. In a perineal prostatectomy population in the pre-PSA era, failure was defined as clinical (biopsy proven local failure or distant metastasis or an elevated prostatic acid phosphatase) (42). Lymph node positive patients were excluded, but not seminal vesicle positive patients. Even with adjuvant radiation in approximately $65 \%$ of the patients, those with Gleason 8-10 cancer had a 5 year clinical failure rate of $57 \%$ and 10 year rate of $80 \%$. In another series of perineal prostatectomy patients (43), with failure defined as a PSA of $>0.5$ $\mathrm{ng} / \mathrm{ml}$, Gleason 8-10 patients had a failure rate of $69 \%$.

As noted previously, the Hopkins group has published various evaluations of their prostatectomy series and as with the effect of positive seminal vesicles they have also evaluated Gleason score. In evaluation of the entire cohort (21) with a median follow up of 5.9 years, $17 \%$ of the patients failed for a 5,10 , and 15 year biochemical recurrence free survival of $84 \%, 72 \%$ and $61 \%$ respectively. Gleason score was the most strongly predictive factor for failure. For patients with a Gleason score of 8-10, with PSA 0-4 $\mathrm{ng} / \mathrm{ml}$, by 5 years, $56 \%$ had failed (79\% by 10 years), with PSA $4.1-10 \mathrm{ng} / \mathrm{ml} \mathrm{63 \%}(85 \%)$, for PSA $10.1-20$ $\mathrm{ng} / \mathrm{ml} 69 \%$ (89\%) and for PSA >20 ng/ml 75\% (93\%). Noteworthy is that for patients with Gleason $7(4+3)$ cancer with a PSA of $4.1-10 \mathrm{ng} / \mathrm{ml}$ and $10.1-20 \mathrm{ng} / \mathrm{ml}$ failure rate at 10 years was $58 \%$ and $69 \%$, respectively. For PSA $>20$, at 5 years it was $57 \%$ and at 10 years it was $80 \%$. In a later update (22) with slightly longer follow up (mean 6.3 years), the failure rate overall for their prostatectomy patients was still $17 \%$. For the Gleason 8-10 patients, 10 year disease free survival was $29 \%$, which dropped to $15 \%$ by 15 years. For Gleason 4+3 patients, 10 and 15 year disease free survival was $33 \%$. In a study of some of the same patients (44), but with exclusion of the highest risk patients (lymph node and seminal vesicle positive and those with adjuvant androgen ablation or radiation), with a median follow up of 6 years, for Gleason 8-9, 5 and 10 year progression free survival $59 \%$ and $35 \%$, respectively. These findings are fairly consistent across studies. In one study (45), patients with Gleason 8-10 cancer had less than 30\% 5 year disease free survival. This improved with subsequent follow up from the same institution (32). For 38 Gleason 8-10 patients with a median follow up of 47 months, 5 and 10 year disease free survival was $49 \%$ and $41 \%$, respectively. The 10 year metastasis free survival was $58 \%$. In another study (24) with somewhat longer follow up (mean 65 months), even though some of the patients received adjuvant radiation therapy, for Gleason 8-10 patients, the 10 year disease free survival rate was 
$32 \%$. For Gleason $4+3$ patients it was $50 \%$. In another study (26) that included adjuvant treatment, Gleason 8-10 patients had a 5 year PSA recurrence free survival of $43 \%$. In a follow up study from the same institution (46) with longer follow up (median 6.6 years), there were 407 Gleason 8-10 patients, almost half $(45 \%)$ received adjuvant treatment and $25 \%$ were $\mathrm{LN}+$. The overall 10 year progression free survival was $36 \%$ and cause specific survival was $85 \%$. For the patients not selected for adjuvant treatment, the 10 year progression free survival was $23 \%$, compared to $53 \%$ for those that received additional treatment.

From the above studies, it is evident that other factors such as pre treatment PSA and the pathological findings have an influence on outcome for the high grade cancers. In a study (28) of 188 Gleason 8-10 patients the $5 \mathrm{yr}$ disease free survival was $71 \%$ (dropping to $56 \%$ at 7 years). For patients with extension outside the gland (pT3a) if margins were negative, 5 yr DFS was $84 \%$ versus $62 \%$ if margins were positive. The same effects of margin status were seen in a composite study (30) of 3 institutions with 318 Gleason $8-10$ patients. Those with positive margins had a $17 \% 7$ year disease free survival compared to $45 \%$ for those with negative margins. This was at a modest median 38 months of follow up, but high grade is so highly predictive of failure, even in a study (47) with short follow up (median 21 months), 51\% of Gleason 8-10 patients had already failed, resulting in a 5 year PSA failure free survival of $40 \%$. Patients with organ confined disease did better $(73 \% 5$ year disease free survival) than those with EPE $(40 \%)$ or SV+ $(30 \%)$. Pretreatment PSA also modified the outcome in Gleason 8-10 patients. In a study (48) utilizing biopsy grade, the most favorable subgroup was Gleason 8-10 patients with a PSA $<10$, who had a $47 \% 5$ year disease free survival, which dropped to $19 \%$ if the PSA was $>10 \mathrm{ng} / \mathrm{ml}$. In a broader context, for PSA $<20$ $\mathrm{ng} / \mathrm{ml}, 5 \mathrm{yr}$ disease free survival was $38 \%$ and if the PSA was $>20 \mathrm{ng} / \mathrm{ml}$, all the patients had failed. For lower grade cancers (Gleason <8), PSA still had a strong influence with a 5 year disease free survival of $55 \%$ for PSA $<10 \mathrm{ng} / \mathrm{ml}$, but dropping to $45 \%$ if PSA up to $20 \mathrm{ng} / \mathrm{ml}$ was included. In another study (38), the 24 month disease free survival for Gleason 8-10 with PSA $<10 \mathrm{ng} / \mathrm{ml}$ was only $59 \%$, dropping to $25 \%$ if the PSA was $>10 \mathrm{ng} / \mathrm{ml}$. For organ confined patients with Gleason 8-10 cancer, the 34 month disease free survival was only $71 \%$. If there was EPE, it was $50 \%$, which was not much different than margin positive at $54 \%$.

As discussed earlier, some studies find that Gleason 7 patients have outcomes comparable to Gleason 8-10 and therefore report them together. In 106 Gleason 7-10 patients with long term follow up (median 7 years), 38\% received adjuvant radiation (41). For the non organ confined patients, only $34 \%$ were free of PSA failure and at 10 years, only $22 \%$. By 10 years, $22 \%$ had died of cancer. In another study (49) evaluating Gleason 7-10 patients, the 5 year PSA recurrence free survival was $42 \%$. For patients with PSA $>20 \mathrm{ng} / \mathrm{ml}$ or Gleason $>7$, the margin negative 5 year biochemical failure free survival was $60 \%$, but with margin positive, it dropped to $15 \%$.

Some studies have found that Gleason $4+3$ patients do worse than Gleason 3+4 patients, with outcomes similar to Gleason 8 patients. In one study, (50) the 354 Gleason $3+4$ patients had a $72 \% 5$ year recurrence free survival (PSA $>0.4 \mathrm{ng} / \mathrm{ml}$ ) compared to $62 \%$ for the 178 Gleason $4+3$ patients. This was not significant on multivariate analysis. In a study considering EPE and margin status (51) for 97 Gleason 4+3 patients with extensive extraprostatic extension and negative margins or Gleason 3+4 with positive margins, the 5 year disease free survival was $55 \%$ and 10 year was $31 \%$. For the 18 Gleason $4+3$ patients with extensive extraprostatic extension and positive margins, it was $39 \%$ and $16 \%$, respectively. Other studies $(35,52)$ also show that primary grade 4 cancers were more likely to fail than grade 3 on univariate analysis, but not on multivariate analysis when considering such factors as seminal vesicle and lymph node involvement.

In summary, as with seminal vesicle involvement, Gleason 8-10 cancer is a consistently strong predictor of failure. In might be possible to identify patients with organ confined disease or low preoperative PSA that might do well, but in most studies, these are very small subgroups and hence the data is tenuous. In a preoperative clinical trial, anyone with a biopsy Gleason of 8-10 was deemed at enough risk to warrant neo adjuvant chemo and hormonal therapy (18). The body of data indicates that Gleason 8-10 patients have a high enough risk of failure to warrant immediate adjuvant treatment. 
Table 2: Effect of high grade (Gleason 8-10) on recurrence post prostatectomy

\begin{tabular}{|c|c|c|c|c|c|c|c|c|}
\hline G1 8-10 & & & & & & & & \\
\hline Study & \# pts & $\begin{array}{l}\text { PSA } \\
\text { Failure }\end{array}$ & $\begin{array}{l}\text { Months } \\
\text { Med f/u } \\
\text { (mean) }\end{array}$ & modifiers & Failure rate & 5 yr DFS & 7 yr DFS & 10 yr DFS \\
\hline $\operatorname{Han}^{21}$ & 2091 & $\geq 0.2$ & 71 & PSA 0-4 & & & & \\
\hline & NS & & & ECE+ & & $44 \%$ & & $21 \%$ \\
\hline & & & & ECE- & & $78 \%$ & & $63 \%$ \\
\hline & & & & PSA 4-10 & & & & \\
\hline & & & & ECE+ & & $37 \%$ & & $15 \%$ \\
\hline & & & & EPE- & & $75 \%$ & & $57 \%$ \\
\hline & & & & PSA 10.1-20 & & & & \\
\hline & & & & $\mathrm{EPE}+$ & & $31 \%$ & & $11 \%$ \\
\hline & & & & EPE- & & $71 \%$ & & $52 \%$ \\
\hline & & & & PSA $>20$ & & & & \\
\hline & & & & $\mathrm{EPE}+$ & & $25 \%$ & & $7 \%$ \\
\hline & & & & EPE- & & $66 \%$ & & -- \\
\hline $\mathrm{Han}^{22}$ & 160 & $>0.2$ & (76) & & & $44 \%$ & $29 \%$ & $15 \%$ \\
\hline Roehl $^{24}$ & 237 & $\geq 0.3$ & (65) & & & & & $32 \%$ \\
\hline $\operatorname{Mian}^{28}$ & 188 & $\geq 0.1$ & 60 & & & $71 \%$ & $56 \%$ & \\
\hline & 50 & & & $\mathrm{EPE}+\mathrm{mar}-$ & & $84 \%$ & & \\
\hline & 16 & & & $\mathrm{EPE}+\mathrm{mar}+$ & & $62 \%$ & & \\
\hline Stephenson ${ }^{30}$ & 118 & $\geq 0.2 \times 2$ & 38 & Mar+ & & & $17 \%$ & \\
\hline & 200 & & & Mar- & & & $45 \%$ & \\
\hline Hull ${ }^{32}$ & 38 & 0.4 & 47 & & & $49 \%$ & & $41 \%$ \\
\hline Frazier 43 & 51 & $>0.5$ & NS & & $69 \%$ & & & \\
\hline Epstein ${ }^{44}$ & 41 & $>0.2$ & $72(78)$ & & & $59 \%$ * & & $35 \%$ \\
\hline Ohori ${ }^{45}$ & $268 \#$ & $>0.4$ & 30 & & & $55 \%$ & & \\
\hline Rodriquez $^{47}$ & 180 & $\geq 0.2$ & 21 & & $51 \%$ & $40 \%$ & & \\
\hline Grossfeld 48 & 77 & $\geq 0.2 \times 2$ & 37 & PSA $<10$ & & $47 \%$ & & -- \\
\hline & 37 & & & PSA $>10$ & & $19 \%$ & & -- \\
\hline
\end{tabular}

DFS $=$ disease free survival based on PSA

Mar+ is margin positive; Mar- is margin negative; EPE+ is extraprostatic extension present; EPE- is extraprostatic extension absent; foc is focal; Ext is extensive; Est is established; Gl is Gleason score. \#Gleason 7-10; * 4 years

Table 3: effect of preoperative PSA on failure

\begin{tabular}{|c|c|c|c|c|c|c|c|c|}
\hline \multicolumn{9}{|l|}{ PSA } \\
\hline Study & \# pts & $\begin{array}{l}\text { PSA } \\
\text { Failure }\end{array}$ & $\begin{array}{l}\text { Months } \\
\text { Med f/u } \\
\text { (mean) }\end{array}$ & modifiers & Failure rate & 5 yr DFS & 7 yr DFS & 10 yr DFS \\
\hline \multirow[t]{2}{*}{$\operatorname{Han}^{22}$} & 351 & \multirow[t]{2}{*}{$>0.2$} & \multirow[t]{2}{*}{ (76) } & $10.1-20$ & & $73 \%$ & $57 \%$ & $54 \%$ \\
\hline & 100 & & & $>20$ & & $60 \%$ & $48 \%$ & $48 \%$ \\
\hline \multirow[t]{2}{*}{ Hull 32} & 164 & \multirow[t]{2}{*}{0.4} & \multirow[t]{2}{*}{47} & \multirow[t]{2}{*}{$10-19.9$} & & $69 \%$ & & $69 \%$ \\
\hline & 68 & & & & & $50 \%$ & & $46 \%$ \\
\hline \multirow[t]{3}{*}{ Stamey55 } & 114 & \multirow[t]{3}{*}{$\geq 0.07$} & \multirow[t]{3}{*}{$64(67)$} & $>10$ & $67 \%$ & -- & -- & -- \\
\hline & 57 & & & $>15$ & $84 \%$ & -- & -- & -- \\
\hline & 30 & & & $>20$ & $93 \%$ & -- & -- & -- \\
\hline Gonzalez $^{59}$ & 115 & $>0.2$ & 67 & $>20$ & $52 \%$ & -- & -- & -- \\
\hline
\end{tabular}

$\mathrm{DFS}=$ disease free survival based on PSA

\section{Prostate Specific Antigen}

PSA has long been recognized as a predictor of failure. Patients with PSA levels in the hundreds and thousands almost always have metastatic disease and if not at presentation, will in short order. In general, the chances of developing systemic disease decreases the lower the PSA. Historically, one of the statistical dividing lines for risk is a PSA of about $20 \mathrm{ng} / \mathrm{ml}$. While patients with levels above that frequently suffer PSA recurrence after treatment, it is not always evi- dent that recurrence is systemic. From a practical standpoint, currently there are very few patients that present with a PSA above $20 \mathrm{ng} / \mathrm{ml}$ and even fewer that undergo surgery. As a result, not too many studies report on PSA as a stand alone factor and as evidenced by our discussion so far, is often considered in refining the meaning of other risk factors. In fact, it is not uncommon when multiple factors are evaluated (especially regarding details of pathology such as lymph node, seminal vesicle, or margin status) that 
PSA is no longer a significant factor on multivariate analysis $(52,53)$.

In a study done of patients from early in the PSA era (55), for patients with peripheral zone cancer and a PSA $>10 \mathrm{ng} / \mathrm{ml}$, only $33 \%$ were cured. If the PSA was greater than $15 \mathrm{ng} / \mathrm{ml}$, the cure rate dropped to $16 \%$ and for PSA $>20 \mathrm{ng} / \mathrm{ml}, 7 \%$. In a study (26) that also included adjuvant treatment, with a mean follow up of 5.6 years, in patients with a PSA $>20 \mathrm{ng} / \mathrm{ml}$, the 5 year biochemical recurrence free survival was $58 \%$. In a large cohort (23) with comparable follow up (mean 6.3 years), for patients with PSA $10.1-20 \mathrm{ng} / \mathrm{ml}$, 5 year disease free survival was $73 \%$ and 10 year was $57 \%$. For PSA $>20 \mathrm{ng} / \mathrm{ml}$, it was $60 \%$ and $48 \%$, respectively. Finally, in a study (32) with slightly shorter follow up (median 47 months), for patients with a PSA of $20-49 \mathrm{ng} / \mathrm{ml}$, the 5 and 10 year recurrence free survival rates were $50 \%$ and $46 \%$, respectively. For those with a PSA of $10-19.9 \mathrm{ng} / \mathrm{ml}$, the 5 and 10 year rates were both $69 \%$.

Some (56) have found that a high preoperative PSA velocity was predictive of increased risk of cancer death, although the inclusion of lymph node positive patients skewed the results negatively; patients with the elevated PSA velocity had a $48 \%$ failure rate, which was similar to Gleason 8-10 patients (54\%). Unfortunately, as this study demonstrated, many patients do not have enough preoperative PSAs to determine velocity. In addition, not all studies have found that preoperative PSA velocity or doubling time predicts for recurrence $(57,58)$. The high number of patients that do not have this information available makes the conclusions uncertain, and hampers it widespread adoption. It is another one of those factors that if available would help support proceeding with treatment in an uncertain situation.

In short, it is unlikely to have patients with an elevated PSA without other high risk findings and it will serve as confirmation that adjuvant treatment might be indicated. As a stand alone factor, certainly it indicates enough risk to warrant adjuvant treatment. The exact pattern of failure in these patients has not been well studied and some of them might benefit from local instead of defaulting to systemic adjuvant treatment. Given the paucity of patients, it will be difficult to refine this in the future.

\section{Extraprostatic extension and positive margins}

Conceptually, as with most cancers, men that have cancer extending outside of the gland and/or positive margins are at a high risk of recurrence. Early it on, it was thought that those patients had such a high risk of recurrence that they were "not curable by surgery alone". (60) As our experience with prostate cancer has evolved to where it is not as advanced at presentation, the prognosis has improved, but those factors do still offer some prediction as to recurrence.

Both extraprostatic extension (EPE) and margin status offer prognostic information. Various studies find that one may be more dominant than the other, but in most cases, it is really hard to separate the two. The likelihood of being significant on multivariate analysis depends on the multiple other factors with which they are evaluated. $(21,33)$ For example, if SV positive or LN positive patients are included, margin status or EPE may not be independently predictive due to the overwhelming risk of failure associated with those two factors. Although at times they are the most predictive factor, as a stand alone factor, they usually don't have the overwhelming failure risk associated with SV positive, LN positive and high grade cancers. With that, it is the additional risk they convey in addition to other factors that make them so important.

The first real challenge is as to how to define extraprostatic extension and margin positivity. EPE is often used interchangeably with extracapsular extension. Since the prostate does not have a complete capsule, it can be argued that EPE is a more accurate description. In simple terms, it means cancer extending outside the prostate proper. That is relatively easy if there is attached fat, but if the prostate edge is bare, then it is more subjective. The same is true with positive margins. It is a relatively easy call if there is cancer out into fat and it is present at the inked cut edge. It is a little more problematic if there is no capsule or fat and then it simply means that there is cancer at the inked edge. This is how an organ confined cancer can have a positive margin; the cancer is to the surface of the bare gland and is in contact with ink. Of course, the ability to detect EPE and positive margins depends on how diligently it is sought. The most complete routine is probably whole mount with uniform step sectioning and then diligent analysis of each and every slide. This is extremely time consuming, so in most instances this degree of scrutiny is rarely routinely undertaken. Suffice it to say, the issue of EPE and margin status is somewhat subjective, so caution should be made in not over interpreting their significance, especially as an isolated finding. The definition and the pathological determination of capsular penetration, extra capsular or prostatic extension, capsular incision and positive margins is not uniform and not straightforward (61), which probably accounts for some of the variability as to how these factors impact on prognosis.

In an early radical retropubic cohort (1969-1993) (62) with a minimum of 10 years of follow up, the 10 
year clinical progression and/or PSA failure free survival was $63 \%$. For patients with no capsular involvement it was $69 \%$, for the 24 with invasion into, but not through, it was similar at $67 \%$, while for the 26 men with invasion through the capsule, it dropped to $39 \%$. In another long term study (23) patients with EPE had a $39 \%$ failure rate and $11 \%$ death rate by 12 years.

Margin status has also been found to be an independent predictor of recurrence. In an early study in perineal prostatectomy patients (63), for patients with positive margins, 5 year biochemical recurrence was $58 \%$, which resulted in a cancer death rate of $40 \%$ at 13.5 years. Patients with positive margins had double the overall death rate $(60 \%)$ as those with organ or specimen confined disease $(30 \%)$.

Multiple other studies (Table 4) have shown that margin positive disease has a $19-64 \%$ (64-70) recurrence rate for a 5 year failure free survival of $37 \%-86 \%$ $(26,30,44,65,69-71)$ and 10 year failure free survival of $26 \%-61 \%(31,44,64)$. If patients have other high risk factors (i.e. PSA $>20 \mathrm{ng} / \mathrm{ml}$ and Gleason $>7$ ) the 5 year recurrence free survival is very low (15\%)(49) Still, some studies have found margin status to be irrelevant. In the first of two studies by the same author (35) (mean follow up of 41 months) on multivariate analysis, LN positive, pathologic stage (i.e. EPE), seminal vesicle involvement and Gleason score were all prognostic at the exclusion of margins or capsular invasion. In the later study (72), (mean follow up 55 months), PSA was the only significant factor on multivariate analysis.

The finding of EPE has some prognostic power independent of margin status. For EPE positive disease, 5 year failure free survival is $48 \%-68 \%(26,71)$.More specifically, for EPE positive margin negative disease, 5 year failure free survival is $48 \%-76 \%(24,32,64)$ and 10 year failure free survival is $46-90 \%$. In patients with both EPE and margin positive disease, 5 year failure free survival is 33-55\% $(24,31,32,64,65,66,73)$ and 10 year failure free survival is $20 \%-53 \%$.

In most studies, while both margin positivity and EPE are each predictive, the two together yield a worse prognosis. In a study that excluded LN positive patients (16), with a median follow up of 121 months, $37 \%$ patients recurred. For organ confined patients, $25 \%$ recurred, which increased to $44 \%$ for EPE but margin negative patients and 64\% with EPE and margin positive patients. Ten year disease free survival was $56 \%$ for EPE positive margin negative and $32 \%$ for EPE positive and margin positive patients, respectively. In another study (74) the margin negative patients had a clinical recurrence rate of $13 \%$ versus 39\% for margin positive. For 5 year PSA progression (PSA $>1.0 \mathrm{ng} / \mathrm{ml}$ ), patients with pathological extension outside the gland (pT3-4) with margins positive had a $52 \%$ (from the graph) progression rate, but was only $25 \%$ if the margins were negative (EPE positive, margin negative). In an updated study for patients with pathologically locally extensive disease (pT3; EPE positive), the 5 and 10 year clinical progression was $34 \%$ and $75 \%$, respectively.

From the preceding, it appears that both EPE and margin involvement have a negative effect on recurrence, although maybe not in all cases to the same independent degree as the factors we have already reviewed (high PSA, Gleason 8-10 cancer and/or seminal vesicle involvement).

For patients with intermediate findings (i.e. Gleason $\leq 7$ ), the addition of EPE and/or positive margins may present enough risk to warrant immediate adjuvant treatment. For example, in a large study (23) with a mean follow up of 6.3 years, patients with <Gleason 7 cancer and extraprostatic extension with negative margins did just as well as patients with organ confined disease, with a 15 year recurrence free survival of $84 \%$. If the margins were positive, it was only $58 \%$. In another large study (24), patients with organ confined disease did moderately well even if they had a high grade cancer and/or PSA $>10 \mathrm{ng} / \mathrm{ml}$ with a 7 year disease free survival rate of $59 \%$. For patients with EPE and PSA $>10 \mathrm{ng} / \mathrm{ml}$, even if they had a well differentiated cancer, the 7 year disease free survival dropped dramatically to $25 \%$. For moderately differentiated cancers (i.e. Gleason 7) with $\mathrm{EPE}$, for PSA $<10 \mathrm{ng} / \mathrm{ml}$, the 7 year disease free survival was $46 \%$, but only $11 \%$ with PSA > $10 \mathrm{ng} / \mathrm{ml}$. Of course, the patients with poorly differentiated tumors and EPE did poorly; with PSA $<10 \mathrm{ng} / \mathrm{ml} \mathrm{46 \%}$ and PSA $>10 \mathrm{ng} / \mathrm{ml} \mathrm{5 \%} 7$ year disease free survival. In another study for the 264 positive margin patients (75), the overall 5 year failure free survival was $80 \%$. The intermediate risk patients (PSA $10-20 \mathrm{ng} / \mathrm{ml}$ or Gleason 7 disease) initially did fairly well with a 5 year disease free survival of $78 \%$, but it dropped precipitously to $23 \%$ at 10 years. The high risk (PSA $>20$ $\mathrm{ng} / \mathrm{ml}$ or Gleason $8-10$ ) patients had $100 \%$ failure by 10 years.

In a more aggressive approach, one study of (34) 862 patients looked specifically at the 2 year failure rate, with the supposition that those patients would be more likely to develop metastatic disease. With that, they proposed that a 2 year failure rate of $>50 \%$ was certainly enough to warrant adjuvant intervention. Patients with EPE and Gleason 7-10 cancers had a uniformly high risk of 2 year failure. For margin negative patients some of the Gleason 7 patients with 
low PSA levels had a relatively more modest risk of failure. For example, in Gleason 7, margin negative, PSA $0-4 \mathrm{ng} / \mathrm{ml}$ patients, the 2 year risk of failure was $18 \%$. Although it can be argued that is a fairly brisk failure rate for just 2 years, it does indicate that some of those patients will do well. As discussed earlier, caution must be exercised in taking these results too literally due to small numbers. This study does raise another potential prognostic factor in that for patients with EPE, there was a difference between patients with established (extensive) margin involvement versus focal, with the latter patients having an average of $28 \%(18-33 \%)$ less risk of failure across all the PSA levels and Gleason scores.

This confirms some of the earlier work by this group (73). In known high risk patients (Gleason 8-10, LN positive, SV positive) those receiving adjuvant treatment were excluded. For patients with Focal EPE and margins negative disease, 5 year PSA recurrence free survival was $69 \%$, dropping to $45 \%$ if there was extensive EPE. In another example (76) for Gleason 7 patients with organ confined disease and negative margins, 5 and 10 year progression free survival were $97 \%$ and $68 \%$, which dropped to $83 \%$ and $48 \%$ with Gleason 7 patients with focal extraprostatic extension positive (with or without positive margins) or established extraprostatic extension and negative margins. For patients with Gleason 7 and established extraprostatic extension and positive margins, the 5 year progression free survival was $50 \%$ and 10 year was $42 \%$.

Several other studies have shown similar results. For example, $(66,77)$ patients with multiple margins had a higher risk of failure $(44 \%, 27 \%)$ than those with a single margin $(21 \%, 15 \%)$. Other studies have reported similar findings $(30,53,67)$, although it is not always an independent predictive factor on multivariate analysis. (78)

It is clear (Table 4) that EPE and margin status have an effect on failure, especially when considered together. It can be argued that the failure risk approaches those of high Gleason score and SV involvement patients, but there are patients with those factors that may not have that high of a risk and the assessment is much more complicated. It would appear that patients with Gleason 7 cancer and the combination of EPE and positive margins have a high enough risk that they should be uniformly considered for adjuvant treatment.

Table 4: effect of extraprostatic extension and positive margins on failure

\begin{tabular}{|c|c|c|c|c|c|c|c|c|c|}
\hline Study & $\#$ pts & $\begin{array}{l}\text { PSA } \\
\text { Failure }\end{array}$ & $\begin{array}{l}\text { monthsMed } \\
\text { f/u (mean) }\end{array}$ & Modifiers & Failure rate & $\begin{array}{l}5 \mathrm{yr} \\
\text { DFS }\end{array}$ & $\begin{array}{l}7 \mathrm{yr} \\
\text { DFS }\end{array}$ & $\begin{array}{l}10 \mathrm{yr} \\
\text { DFS }\end{array}$ & $\begin{array}{l}15 \mathrm{yr} \\
\text { dfs }\end{array}$ \\
\hline \multirow[t]{2}{*}{ Swanson ${ }^{16}$} & 39 & $>0.3$ & 121 & $\mathrm{EPE}+\mathrm{mar}-$ & $44 \%$ & $66 \%$ & & $56 \%$ & \\
\hline & 105 & & & EPE+mar+ & $64 \%$ & $52 \%$ & & $32 \%$ & \\
\hline \multirow[t]{2}{*}{ Han 22} & 135 & $>0.2$ & (76) & $\mathrm{EPE}+\mathrm{Gl}>6$ mar + & & $58 \%$ & $42 \%$ & $42 \%$ & $33 \%$ \\
\hline & 326 & & & $\mathrm{EPE}+\mathrm{Gl}>6$ mar - & & $80 \%$ & & $61 \%$ & $59 \%$ \\
\hline \multirow[t]{2}{*}{ Roehl 24} & 632 & $\geq 0.3$ & (65) & $\mathrm{EPE}+\mathrm{mar}+$ & & & & $53 \%$ & \\
\hline & 255 & & & EPE+mar- & & & & $62 \%$ & \\
\hline \multirow[t]{4}{*}{ Stephenson ${ }^{30}$} & 1501 & $\geq 0.2 \times 2$ & 38 & Mar + & & & $60 \%$ & & \\
\hline & 5659 & & & Mar - & & & $88 \%$ & & \\
\hline & 501 & & & $\mathrm{EPE}+\mathrm{Mar}+$ & & & $52 \%$ & & \\
\hline & 928 & & & $\mathrm{EPE}+\mathrm{Mar}-$ & & & $74 \%$ & & \\
\hline \multirow[t]{3}{*}{ Karakiewiz $^{31}$} & 1083 & $0.1-0.4$ & 25 & EPE+mar- & & $66 \%$ & & $46 \%$ & \\
\hline & 613 & & & EPE-mar+ & & $74 \%$ & & $61 \%$ & \\
\hline & 941 & & & ECE+Mar+ & & $43 \%$ & & $25 \%$ & \\
\hline \multirow[t]{2}{*}{ Hull ${ }^{32}$} & 251 & 0.4 & 47 & $\mathrm{EPE}+\mathrm{mar}-$ & & $76 \%$ & & $71 \%$ & \\
\hline & 126 & & & mar+ & & $42 \%$ & & $36 \%$ & \\
\hline Kupelian $^{49}$ & 195 & $>0.2$ & 41 & Mar+ & & $36 \%$ & & & \\
\hline Paulson 63 & 225 & $>0.4$ & NS & Mar + & & $58 \%$ & & & \\
\hline \multirow[t]{3}{*}{ Pfitzenmaier ${ }^{64}$} & 60 & $\geq 0.2$ & 62 & Mar+ & $64 \%$ & $38 \%$ & & $26 \%$ & \\
\hline & -- & & & ECE+mar+ & & $33 \%$ & & $20 \%$ & \\
\hline & -- & & & $\mathrm{ECE}+\mathrm{mar}-$ & & $62 \%$ & & $46 \%$ & \\
\hline \multirow[t]{3}{*}{ Cheng 65} & 109 & $>0.2$ & (70) & Mar + & & $70 \%$ & & & \\
\hline & 72 & & & Mar+ EPE- & & $78 \%$ & & & \\
\hline & 37 & & & Mar+ EPE+ & & $55 \%$ & & & \\
\hline \multirow[t]{7}{*}{ Simon 66} & 350 & $>0.3$ & (46) & Mar+ & $19 \%$ & & & & \\
\hline & 586 & & & Mar- & $7 \%$ & & & & \\
\hline & 268 & & & $\mathrm{EPE}+$ & $29 \%$ & & & & \\
\hline & 87 & & & Mar+EPE+ & $39 \%$ & & & & \\
\hline & 153 & & & Mar+ Gl7 & $20 \%$ & & & & \\
\hline & 50 & & & Mar+G18-10 & $52 \%$ & & & & \\
\hline & 121 & & & Mar+ PSA10-20 & $31 \%$ & & & & \\
\hline
\end{tabular}




\begin{tabular}{|c|c|c|c|c|c|c|c|c|c|}
\hline & 47 & & & Mar & $S A>20$ & $64 \%$ & & & \\
\hline Pettus 67 & 28 & $0.2 \times 2$ & $53(55)$ & Api & & $21 \%$ & $79 \%$ & & $79 \%$ \\
\hline & 57 & & & Foca & & $26 \%$ & $84 \%$ & & $74 \%$ \\
\hline & 13 & & & Mul & & $31 \%$ & $69 \%$ & & $69 \%$ \\
\hline Vis 68 & 66 & $\geq 0.1$ & 81 & Mar & & $33 \%$ & & & \\
\hline Mann 70 & 128 & $>0.1$ & 68 & Mar & & & $86 \%$ & $75 \%$ & \\
\hline & 387 & & & Mar & & & $95 \%$ & $88 \%$ & \\
\hline & 194 & & 54 & Mar & & & $84 \%$ & $56 \%$ & \\
\hline & 633 & & & Mar & & & $95 \%$ & $82 \%$ & \\
\hline Kupelian $^{71}$ & 144 & $>0.2$ & 36 & Mar & & & $37 \%$ & & \\
\hline & 206 & & & EPE & & & $48 \%$ & & \\
\hline $\mathrm{D}^{\prime}$ Amico 72 & 57 & $>$ & 57 & Gl & Foc EPE+ mar- & & $69 \%$ & & \\
\hline & 22 & undetectable & & $2-7$ & Ext EPE+ mar- & & $45 \%$ & & \\
\hline & 118 & & & & $\mathrm{EPE}+\mathrm{Mar}+$ & & $33 \%$ & & \\
\hline Alkhateeb ${ }^{75}$ & 264 & $\geq 0.4$ & 79 & Mar & & & $74 \%$ & & $50 \%$ \\
\hline
\end{tabular}

*all patients failure defined at 2 years Mar+ is margin positive; Mar- is margin negative; EPE+ is extraprostatic extension present; EPE- is extraprostatic extension absent; foc is focal; Ext is extensive; Est is established; Gl is Gleason score

\section{Modifying factors}

In trying to predict risk of recurrence after radical prostatectomy, numerous other potential modifying risk factors that have been evaluated. Unfortunately, even if they were shown to be positive on multivariate analysis, they are rarely evaluated as to how they modify or improve the standard factors, so their utility remains questionable. Certainly they have not been proven to be powerful enough a predictor to be uniformly adopted. It is not unreasonable to consider these factors in patients who otherwise have borderline risk where the presence of absence of these factors might aid in the final decision-making.

One of the factors that has been evaluated is that of age. It doesn't take a study to tell us that age will have an effect on overall survival, but it is worth asking if younger or older patients have a higher risk of cancer mortality. One study (79) with extremely short follow up (median 19 months), showed on multivariate analysis that men younger than 50 years of age did better than those over 70 . This was confirmed by another study (80) and a third study (81) showed that patients older than 70 had significantly worse biochemical failure free survival than those younger than 70. An additional study showed that patients $\leq$ 60 years of age had about $15 \%$ better biochemical control at 36 months than older patients (69). The benefit of younger age was confirmed on multivariate analysis. Finally, in (28) seminal vesicle positive patients, age was predictive of recurrence on multivariate analysis with older patients having a shorter time to recurrence. In most studies, younger aged patients are in the minority and there are at least an equal number of other studies that have shown age has no impact on recurrence. $(24,53,82-84)$ With that, it appears the effect of age on recurrence is equivocal.

Some studies seem to show that race has an impact on recurrence, with black men having a higher recurrence rate $(48,85)$. This has been an inconsistent finding with most studies not finding a connection, $(24,86-88)$ so as with age, the significance of race remains uncertain.

A pathologic finding that has been variable as a prognostic factor is that of perineural invasion (PNI). Ostensibly, it is a pathway that the cancer can follow to extend outside of the gland. In many studies that report on it, it is an observational finding. For example, in one study (89), of the 17 patients that recurred, $14(82 \%)$ had perineural invasion. Other than that observation, no real correlation of PNI with failure was possible. When considered in conjunction with other factors such as extraprostatic extension and positive margins, it is not independently associated with recurrence. $(72,90,91,98)$. Although it sounds ominous, perineural invasion is not a strong independent predictor of failure.

Another factor that logic would dictate makes sense as a predictor of failure is that of tumor volume. It would seem that the larger cancers would be harder to eradicate. As a stand alone factor, its predictive power would be somewhat mitigated by other predictive factors, such as PSA, Gleason score, and pathological findings as they are often also unfavorable in large tumors. There are various ways of determining or estimating tumor volume. The most exact of which is to mount the entire specimen, carefully step section it and measure the amount of cancer slice by slice. This is not practical for most pathology departments and there are unresolved issues such as how to account for the multifocality of cancer (i.e. whether to add them all together versus just account for the dominant lesion) (92). Some studies have found what appears to be an association between cancer volume and outcome. In a paper of perineal prostatectomy patients (43) tumor volume $>25 \%$ was a significant predictor of failure on multivariate analysis. For tumor volume of $\leq 25 \%$, the failure rate was $\leq 25 \%$. For 
volumes $>25 \%$, it was $57-88 \%$. In another study of patients from early in the PSA era (1983-1992) (55), for a cancer volume of 2-6 cc, the cure rate (non-rising PSA) was $55 \%$, for $6-12 \mathrm{cc}, 27 \%$ and for $>12$ cc only $3 \%$. In this study, the primary determinants of failure were Gleason pattern $4 / 5$ and cancer volume. Unlike most studies, margin and SV positivity were not predictive when volume was considered. Volume can contribute additional information. In a study of seminal vesicle positive patients, tumor volume actually added some prognostic information that were verified on multivariate analysis (28). It some cases, the predictive ability also holds true for relatively small tumors (26). Patients with tumors $>3 \mathrm{~mm}$ had a 5 year PSA failure free survival of $68 \%$, while for those with tumors $<3 \mathrm{~mm}, 82 \%$. Contrary to the above findings, there are several studies that have found other factors displace volume as a predictive factor. $(53,93)$. In one example,(94) while patients with large volume $(>12$ $\mathrm{cm} 3$ ) had a much worse biochemical failure free survival at 5 yrs (38\%) than smaller volume tumors, it was not significant on multivariate analysis when considered with other factors. Another study (95) where the volume was visually estimated, patients with $<10 \%$ cancer had a 5 year disease free survival of $94 \%$, for $10-20 \%$ volume, $91 \%$, and for $>20 \%$ volume $82 \%$, but volume was not predictive on multivariate analysis.

Another way of evaluating cancer volume that eliminates having to physically determine volume is that of PSA density. This is determined by looking at the surgical volume of the entire gland in relation to the total PSA.(96). High risk patients were defined as any patient with a PSA density of $>0.7$ or any patient with Gleason 8-10. The 5 year PSA failure free survival was $21 \%$. For intermediate risk patients (density $<0.3$, Gleason 7 or Gleason 2-7 and density $0.3-0.7$ ), it was $52 \%$. The results in a separate group of patients were much better than this with a 5 year failure free survival of $70 \%$ for the high risk patients and $78 \%$ for the intermediate risk, respectively. They did find that PSA density was better than PSA on multivariate analysis. As a factor in PSA density, gland size may have some predictive power. In one study of prostatectomy patients with extraprostatic extension and/or positive margins (69), those with glands $<30$ grams had a $10-20 \%$ higher progression rate than those with $>30$ gram glands. Another study showed that a gland size of $40 \mathrm{cc}$ gland had the same risk of recurrence as positive margins that decreased as the gland got larger. (97)

As another measure of volume, there has been great interest in using the biopsy cores to predict outcome. One of the benefits would be to supply some additional prognostic information before the primary treatment was even undertaken. Unfortunately, in standard practice, a high level of detail about the biopsies is not uniformly available. For example, in the SEARCH database, only about half the patients had enough information to analyze (98). In addition, while the needle biopsies do predict volume, there is a wide variation in accuracy. (99) With these limitations, in the first SEARCH study, utilizing only preoperative parameters, the total percent of positive biopsy tissue (length of cancer/total cumulative length of all the cores) was the strongest predictors of recurrence. (98). In a concurrent study of the same patients (100), that wasn't a factor, rather the core density, defined as the per cent of total cores positive from each side. With that, having $>67 \%$ of the cores from the predominant side was the biggest predictor of failure. These results would have to be considered preliminary as the primary endpoint was 2 year failure (with a median follow up of 27 months). Patients with a $>28 \%$ two year failure were patients with $>67 \%$ cores positive on the dominant side with Gleason 7 and PSA $>10$ or Gleason 8-10 with any PSA or Gleason 8-10 with PSA >20 and at least $34 \%$ positive cores. Of course there are multiple different ways to utilize the core information. In another large study cited above (39), it wasn't the dominant side per cent positive cores, but the overall number that was predictive. . Other studies (101) have shown on multivariate analysis that the percentage of positive biopsies was predictive. Still other studies have shown that the percentage of positive cores could mitigate the risk of high grade cancer (102). For example, in high risk patients (defined as PSA $>20$, or Gleason $8-10$ or stage T2C/T3 disease), the overall 5 year recurrence rate at a median of 40 months was $36 \%$, but was $24 \%$ for $0-33 \%$ cores positive, $34 \%$ for $34-66 \%$ cores positive and $59 \%$ for $>66 \%$ cores positive. This was significant on multivariate analysis. Another study (54) showed similar findings. They found in a post operative population that a low number of positive cores could mitigate the risk of high grade. Overall the finding of $>28 \%$ cores was a poor prognosis, In Gleason 8-9 patients with pT2-3 cancer and margin negative with $<28 \%$ positive cores there was an $85 \% 5$ year progression free survival which dropped to $54 \%$ with $>28 \%$ positive cores. In other studies, it's not the percentage of total cores taken that is predictive, but the amount of any core that is involved. For example, in non-palpable prostate cancer (T1C)(84) that were Gleason 7-10 or PSA > $10 \mathrm{ng} / \mathrm{ml}$, if $<50 \%$ of any single core was positive, the 10 year disease free survival was $85 \%$, compared to $56 \%$ if $>50 \%$ of any core was positive. In another, the total length of high grade $(4 / 5)$ cancer in the biopsy 
cores was predictive for recurrence (68). They found that for $>10 \mathrm{~mm}$ of Gleason grade $4 / 5$ cancer, recurrence was $50 \%$ (PSA $>0.1 \mathrm{ng} / \mathrm{ml}$ ) and for $3-10 \mathrm{~mm}$ was $<40 \%$. Others (103) have found that percentage positive cores have no predictive value.

The problem in this and in many of the studies is with these multiple subdivisions, many of the subgroups are very small ( $<10$ patients). Also, the way of obtaining the cores is user dependent, with no common standards. Grids are rarely used and one could imagine how directed biopsies to the area of palpable tumor rather than uniformly throughout the gland could influence results. Overall, caution must be used to avoid over interpreting the results. With that, it is fairly consistent that patients with more than $2 / 3$ positive cores have a higher risk of failure than patients with a lesser number. In the case of Gleason 7 patients, it is probably enough to recommend treatment, whereas if there are $<1 / 3$ positive cores with other factors negative, it might give impetus to observe.

Other factors that have received intermittent interest is that of micro vascular density and ploidy. Their utility has not been well proven (104) and we will mention them only briefly as they are not routinely obtained and are unlikely to be available to most clinicians. As new vessel formation is necessary for a cancer to grow, it is not uncommon to find increased vessel formation in many tumors. The degree of proliferation is considered by some to be a marker of aggressiveness and it's mediators such as vascular endothelial growth factor (VEGF) and it's receptors such as VEGFR 1-3 are targets of therapy in many cancers. In prostate cancer, it appears in some studies that high micro vascular density (MVD) is associated with progression, in some cases strongly so(105-107), but just as many other studies show that when considered with multiple factors, it is not predictive on multivariate analysis. (108-111).

Another factor that received some attention in the pre-PSA era was that of ploidy, but in spite favorable reports, has also never become widely adapted. Early studies showed that patients with non-diploid tumors were more likely to fail, sometimes with a dramatic difference (112), but except in rare cases the effect on overall survival was either negligible or modest. $(113,114)$ The patients that did the worst were those with anueploid tumors, but they only accounted for a small percentage of the patients $(\sim 10 \%)$ and in some cases, there was not much difference between the diploid and tetraploid patients (115). It did seem to offer some differentiation for patients with low grade tumors with a 94\% 10 year disease free survival for diploid versus $58 \%$ for non-diploid. In high grade tumors the differentiation was modest. Other studies showed no predictive survival difference on ploidy analysis $(116,117)$. While it is intriguing to consider that ploidy might help determine risk, especially in the intermediate risk patients, the results have been inconsistent and inconclusive.

\section{Modeling factors}

As evidenced from the preceding discussion, there are multiple factors that may predict for failure after prostatectomy. The best recognized are PSA, Gleason score and the details of pathological stage. Their effects are not totally independent of each other and attempts have been made to correlate them with each other. The first models were that of risk grouping. One of the earlier grouping of surgery patients relied on clinical, rather than pathological staging, so is archaic by today's standards. (118). Over time, it was thought that perhaps the predictive ability for an individual patient could be refined by improving on the risk clustering models. Attempts have been made to incorporate other specific prognostic variables (such as margin status) to improve the predictive accuracy. These models are developed from a population of patients with established outcomes, so still are subject to the uncertainties of the selection and exclusion bias's that are inherent to that data. Using regression analysis, multiple factors are evaluated, which should reduce the error of any one variable, but at the same time presents the risk of introducing other artifact. Still, the nomograms associate continuous risk variables collectively and their proponents maintain that they provide the best estimate of probability of recurrence. As designed, individual predictive factors are assigned a risk number (based on proportional risk analysis) and when added together yield a total number that can be associated with risk of failure at various time points. These nomograms, when tested against the population used to design them are about $80 \%$ accurate (concordance incidence of 0.8 ). They are not quite as robust against other populations, but appear to be an improvement over the earlier, simpler models. It is interesting to look at the assigned risk of the various factors (Table 5) and how they differ from study to study (even though some of the nomograms contain some of the same patients)(119-121). The points themselves are arbitrary, but it is informative to look at their potential proportional contribution to a given risk of failure (i.e. for a $70 \%$ risk at 10 years, $60 \%$ at 7 years, $50 \%$ at 5 years and $30 \%$ at 2 years, a somewhat linear correlation). The differences in percentage contribution of the factors illustrates that even in these more sophisti- 
cated models factors such as patient selection, factor selection, and length of follow up have an influence on their contribution to failure. For example, in our earlier discussion, seminal vesicle involvement is an overwhelming predictor of failure, but as can be seen from the table, in all but one study shown, it wouldn't even contribute more than $20 \%$ of the risk in determining the defined failure. The reminder here is that the high risk factors (SV, margin, ECE, and Gleason 8-10) often cluster together to some degree and is what drives failure. It pays not to be too dogmatic about the high risk features, but to try to tease out patients with some of these factors that may have a low risk of failure (i.e. Gleason 6 with positive SV+) is actually at the fringes of the data due to smaller patient numbers. The place that it may be more important is in patients that are otherwise intermediate risk, such as one with Gleason 7 cancer, a PSA of 8, ECE positive and margin and SV negative. This patient would be well below our arbitrary risk threshold based on these nomograms, but if he had extensive EPE or was black, that may be enough to recommend treatment.

Table 5: Contribution of individual nomogram risk factors on give risk of failure

\begin{tabular}{|c|c|c|c|c|c|}
\hline study & Stephenson ${ }^{119}$ & Kattan $^{120}$ & Kattan 121 & Schroeck ${ }^{97}$ & Walz $^{122}$ \\
\hline $\begin{array}{l}\text { Other factors not } \\
\text { shown below }\end{array}$ & Year of surgery & surgeon experience & Capsule invasion & $\begin{array}{l}\text { Race, year of surgery, } \\
\text { prostate weight }\end{array}$ & None \\
\hline $\begin{array}{l}\text { Points for failure } \\
\text { threshold }\end{array}$ & $\begin{array}{l}172 \\
\text { Points for } 10 \text { yr failure } \\
>70 \%\end{array}$ & $\begin{array}{l}240 \text { points for } \\
10 \text { yr failure }>70 \%\end{array}$ & $\begin{array}{l}200 \text { points for } 7 \text { year failure } \\
>60 \%\end{array}$ & $\begin{array}{l}150 \text { points \# for } 5 \mathrm{yr} \\
\text { failure }>50 \%\end{array}$ & $\begin{array}{l}115 \text { points for } \\
2 \mathrm{yr} \text { failure }>30 \%\end{array}$ \\
\hline \multicolumn{6}{|l|}{$\begin{array}{l}\text { Risk factor } \\
\text { points / \% of points } \\
\text { of failure thre- } \\
\text { shold }\end{array}$} \\
\hline LN+ & $11(6 \%)$ & $35(15 \%)$ & $28(14 \%)$ & ---- & $33(29 \%)$ \\
\hline ECE+ & $22(13 \%)$ & $35(15 \%)$ & $54(27 \%)^{*}$ & $10(7 \%)$ & $27(23 \%)$ \\
\hline SV+ & $23(13 \%)$ & $31(13 \%)$ & $26(13 \%)$ & $28(19 \%)$ & $49(43 \%)$ \\
\hline Mar + & $10(6 \%)$ & $35(15 \%)$ & $34(17 \%)$ & $35(23 \%)$ & $23(20 \%)$ \\
\hline Gl 4-6 & $0(0 \%)$ & $0(0 \%)$ & $<6(<3 \%)$ & $0(0 \%)$ & $0(0 \%)$ \\
\hline Gl 7 & -- & $44(18 \%)$ & $\overline{3} 0(15 \%)$ & -- & $54(47 \%)$ \\
\hline $3+4$ & $14(8 \%)$ & -- & -- & $16(11 \%)$ & -- \\
\hline $4+3$ & $33(19 \%)$ & -- & -- & $40(27 \%)$ & -- \\
\hline \multirow[t]{4}{*}{ Gl 8-10 } & $47(27 \%)$ & $88(37 \%)$ & -- & $49(33 \%)$ & $100(87 \%)$ \\
\hline & -- & -- & $46(23 \%)$ & -- & -- \\
\hline & -- & -- & $59(30 \%)$ & -- & -- \\
\hline & -- & -- & $72(36 \%)$ & -- & -- \\
\hline PSA 2 & $72(42 \%)$ & $13(5 \%)$ & $65(33 \%)$ & $15(10 \%)$ & $2(2 \%)$ \\
\hline PSA 4 & $77(45 \%)$ & $28(12 \%)$ & $78(39 \%)$ & $30(20 \%)$ & $4(3 \%)$ \\
\hline PSA 5 & $80(47 \%)$ & $35(15 \%)$ & $82(41 \%)$ & $34(23 \%)$ & $5(4 \%)$ \\
\hline PSA 6 & $82(48 \%)$ & $42(18 \%)$ & $84(42 \%)$ & $37(25 \%)$ & $6(5 \%)$ \\
\hline PSA 8 & $83(48 \%)$ & $53(22 \%)$ & $88(44 \%)$ & $43(29 \%)$ & $9(8 \%)$ \\
\hline PSA 10 & $85(51 \%)$ & $60(25 \%)$ & $92(46 \%)$ & $50(33 \%)$ & $11(10 \%)$ \\
\hline 15 & $87(51 \%)$ & $71(30 \%)$ & $93(47 \%)$ & $58(39 \%)$ & $16(14 \%)$ \\
\hline 20 & $92(53 \%)$ & $73(30 \%)$ & $93(47 \%)$ & $65(43 \%)$ & $22(19 \%)$ \\
\hline 30 & $93(54 \%)$ & $77(32 \%)$ & $94(47 \%)$ & $73(49 \%)$ & $33(27 \%)$ \\
\hline 50 & $97(56 \%)$ & $83(35 \%)$ & $96(48 \%)$ & $85(57 \%)$ & $54(47 \%)$ \\
\hline
\end{tabular}

*average of focal (51 pts) and extensive EPE (57 pts)

\#Used a $40 \mathrm{cc}$ prostate which accounts for 35 points

\section{Summary}

The adjuvant radiation studies defined high risk patients as those with positive seminal vesicles (1-3), EPE(1-3), and/or positive margins(1-2). Those studies have unequivocally shown that radiation can reduce biochemical failure. The SWOG study (1), with its much longer follow up, has shown both a metastasis free and overall survival. Although the available data (123) indicates the long term toxicity of the adjuvant therapy group is similar to the observation group, there is concern that not all the patients that would have qualified for the studies really have the recurrence risk to warrant immediate treatment. from the available literature, as reviewed above, it appears that patients with positive seminal vesicles, or Gleason $8-10$, or PSA $>20 \mathrm{ng} / \mathrm{ml}$ have high enough risk to warrant treatment. In addition, patients with EPE or margin positive disease (especially if they have both) 
and are Gleason 7 or higher warrant treatment. Factors such as multifocal or large tumors as measured by biopsy core involvement add further support to treating those patients up front rather than waiting for failure.

\section{Conflict of Interest}

The authors have declared that no conflict of interest exists.

\section{References}

1. Thompson IM, Tangen CM, Paradelo J, et al. Adjuvant radiotherapy for pathological T3N0M0 prostate cancer significantly reduces risk of metastases and improves survival: long-term followup of a randomized clinical trial. J Urol. 2009; 181(3):956-962.

2. Bolla M, van Poppel H, Collette L, et al. Postoperative radiotherapy after radical prostatectomy: a randomised controlled trial (EORTC trial 22911). Lancet 2005; 366(9485): 572-578 .

3. Wiegel T, Bottke D, Steiner U, et al. Phase III postoperative adjuvant radiotherapy after radical prostatectomy compared with radical prostatectomy alone in pT3 prostate cancer with postoperative undetectable prostate-specific antigen: ARO 96-02/ AUO AP 09/95. J Clin Oncol. 2009;27:2924-30.

4. Klotz L. Low-risk prostate cancer can and should often be managed with active surveillance and selective delayed intervention. Nat Clin Pract Urol. 2008 ;5:2-3.

5. Nielsen ME, Trock BJ, Walsh PC. Salvage or adjuvant radiation therapy: counseling patients on the benefits. J Natl Compr Canc Netw. 2010 ;8:228-37.

6. Collette L, Burzykowski T, Schröder FH. Prostate-specific antigen (PSA) alone is not an appropriate surrogate marker of long-term therapeutic benefit in prostate cancer trials. Eur J Cancer. $2006 ; 42: 1344-50$.

7. Lofters A, Juffs HG, Pond GR, et al: "PSA-itis": knowledge of serum prostate antigen and other causes of anxiety in men with metastatic prostate cancer. J Urol 2002; 168:2516-2520

8. Jemal A, Siegel R, Ward E, et al. Cancer statistics, 2009. CA Cancer J Clin. 2009; 59:225-49.

9. Cooperberg MR, Broering JM, Carroll PR. Time trends and local variation in primary treatment of localized prostate cancer. J Clin Oncol. 2010; 28:1117-23.

10. Crawford ED, Eisenberger MA, McLeod DG, et al: A controlled trial of leuprolide with and without flutamide in prostatic carcinoma. N Engl J Med 1989; 321:419-429.

11. Tannock, IF, de Wit R, Berry WR, et al. Docetaxel plus Prednisone or Mitoxantrone plus Prednisone for Advanced Prostate Cancer. N Engl J Med 2004 351: 1502-1512.

12. Pound CR, Partin AW, Eisenberger MA, et al. Natural history of progression after PSA elevation following radical prostatectomy. JAMA. 1999; 281:1591-7.

13. Allsbrook WC, Mangold KA, Johnson $\mathrm{MH}$, et al. Interobserver reproducibility of Gleason grading of prostatic carcinoma: urologic pathologists. Hum Pathol 2001. 32:74-80.

14. Steinberg DM, Sauvageot J, Piantadosi S, et al. Correlation of prostate needle biopsy and radical prostatectomy Gleason grade in academic and community settings. Am J Surg Pathol. 1997, 21:566-76.

15. Swanson GP, Hussey MA, Tangen CM, et al. SWOG 8794.Predominant treatment failure in postprostatectomy patients is local: analysis of patterns of treatment failure in SWOG 8794. J Clin Oncol. 2007; 25:2225-9.
16. Swanson GP, Riggs M, Hermans M. Pathologic findings at radical prostatectomy: risk factors for failure and death. Urol Oncol. 2007;25:110-4.

17. Freedland SJ, Humphreys EB, Mangold LA, et al. Risk of prostate cancer-specific mortality following biochemical recurrence after radical prostatectomy. JAMA 2005; 294: 433-9.

18. Eastham JA, Kelly WK, Grossfeld GD, et al. Cancer and Leukemia Group B. Cancer and Leukemia Group B (CALGB) 90203: a randomized phase 3 study of radical prostatectomy alone versus estramustine and docetaxel before radical prostatectomy for patients with high-risk localized disease. Urology. 2003;62:55-62.

19. McAleer SJ, Shultz D, Whittington R, et al. PSA outcome following radical prostatectomy for patients with localized prostate cancer stratified by prostatectomy findings and the preoperative PSA level. Urol Oncol. 2005;23:311-317.

20. Khan MA, Partin AW, Mangold LA, et al. Probability of biochemical recurrence by analysis of pathologic stage, Gleason score, and margin status for localized prostate cancer. Urology. 2003; 62:866-71.

21. Han M, Partin AW, Zahurak M, et al. Biochemical (prostate specific antigen) recurrence probability following radical prostatectomy for clinically localized prostate cancer. J Urol. 2003; 169:517-23

22. Han M, Partin AW, Pound CR, et al: Long-term biochemical disease-free and cancer-specific survival following anatomic radical retropubic prostatectomy: The 15-year Johns Hopkins Experience. Urol Clin North Am 2001; 28:555-565.

23. Pierorazio PM, Epstein JI, Humphreys E, et al. The significance of a positive bladder neck margin after radical prostatectomy: the American Joint Committee on Cancer Pathological Stage T4 designation is not warranted. J Urol. 2010 ;183:151-7.

24. Roehl KA, Han M, Ramos CG, et al. Cancer progression and survival rates following anatomical radical retropubic prostatectomy in 3,478 consecutive patients: long-term results. J Urol. 2004;172:910-4.

25. Catalona WJ and Smith DS. Cancer recurrence and survival rates after anatomic radical retropubic prostatectomy for prostate cancer: intermediate-term results. J Urol 1998; 160: 2428-34.

26. Blute ML, Bergstralh EJ, Iocca A, et al. Use of Gleason score, prostate specific antigen, seminal vesicle and margin status to predict biochemical failure after radical prostatectomy. J Urol. 2001; 165:119-25.

27. Trapasso JG, deKernion JB, Smith RB, et al. The incidence and significance of detectable levels of serum prostate specific antigen after radical prostatectomy. J Urol. 1994 Nov;152(5 Pt 2):1821-5.

28. Mian BM, Troncoso P, Okihara K, et al. Outcome of patients with Gleason score 8 or higher prostate cancer following radical prostatectomy alone. J Urol, 2002; 167: 1675-80.

29. Sofer M, Savoie M, Kim SS, et al. Biochemical and pathological predictors of the recurrence of prostatic adenocarcinoma with seminal vesicle invasion. J Urol. 2003; 169:153-6.

30. Stephenson AJ, Wood DP, Kattan MW, et al. Location, extent and number of positive surgical margins do not improve accuracy of predicting prostate cancer recurrence after radical prostatectomy. J Urol. 2009 ;182:1357-63.

31. Karakiewicz PI, Eastham JA, Graefen M, et al. Prognostic impact of positive surgical margins in surgically treated prostate cancer: multi-institutional assessment of 5831 patients. Urology. 2005;66:1245-50.

32. Hull GW, Rabbani F, Abbas F, et al. Cancer control with radical prostatectomy alone in 1,000 consecutive patients. J Urol 2002, 167:528-34.

33. Salomon L, Anastasiadis AG, Johnson CW, et al. Seminal vesicle involvement after radical prostatectomy: predicting risk factors for progression. Urology 2003, 62(2):304-9. 
34. D'Amico AV, Whittington R, Malkowicz SB, et al. The combination of preoperative prostate specific antigen and postoperative pathological findings to predict prostate specific antigen outcome in clinically localized prostate cancer. J Urol. 1998;160(6 pt 1):2096-2101.

35. Quinn DI, Henshall SM, Haynes A-M, et al. Prognostic significance of pathologic features in localized prostate cancer treated with radical prostatectomy: implications for staging systems and predictive models. J Clin Oncol 2001, 19:3692-3705.

36. Tefilli MV, Gheiler EL, Tiguert R, et al. Prognostic indicators in patients with seminal vesicle involvement following radical prostatectomy for clinically localized prostate cancer. J Urol. 1998;160(3 Pt 1): 802-6.

37. Freedland SJ, Aronson WJ, Presti JC, et al. Predictors of prostate-specific antigen progression among men with seminal vesicle invasion at the time of radical prostatectomy. Cancer 2004;100: 1633-8

38. Tefilli MV, Gheiler EL, Tiguert R, et al. Should Gleason score 7 prostate cancer be considered a unique grade category? Urology 1999; 53: 372-377.

39. D'Amico AV, Whittington R, Malkowicz SB, et al. Utilizing predictions of early prostate-specific antigen failure to optimize patient selection for adjuvant systemic therapy trials. J Clin Oncol. 2000; 18:3240-6.

40. Swanson GP, Goldman B, Tangen CM, et al. Southwest Oncology Group 8794.The prognostic impact of seminal vesicle involvement found at prostatectomy and the effects of adjuvant radiation: data from Southwest Oncology Group 8794. J Urol. 2008; 180:2453-7.

41. Oefelein MG., Smith ND., Grayhack JT, et al. Long-term results of radical retropubic prostatectomy in men with high grade carcinoma of the prostate. J Urol. 1997; 158: 1460-5.

42. Paulson DF, Moul JW, Walther PJ. Radical prostatectomy for clinical stage T1-2N0M0 prostatic adenocarcinoma: long-term results. J Urol. 1990; 144:1180-4.

43. Frazier HA, Robertson JE, Humphrey PA, et al. Is prostate specific antigen of clinical importance in evaluating outcome after radical prostatectomy. J Urol. 1993; 149:516-8.

44. Epstein JI, Partin AW, Sauvageot J, et al: Prediction of progression following radical prostatectomy: a multi-variate analysis of 721 men with long term follow-up. Am J Surg Pathol 1996; 20: 286-292.

45. Ohori M., Goad JR., Wheeler TM, et al. Can radical prostatectomy alter the progression of poorly differentiated prostate cancer? J Urol. 1994; 152: 1843-9.

46. Lau WK, Bergstralh EJ, Blute ML, et al. Radical prostatectomy for pathological Gleason 8 or greater prostate cancer: influence of concomitant pathological variables. J Urol. 2002; 167:117-22.

47. Rodriguez-Covarrubias F, Larre S, De La Taille A, et al. The outcome of patients with pathological Gleason score $>$ or $=8$ prostate cancer after radical prostatectomy. BJU Int. 2008; 101:305-7.

48. Grossfeld GD, Latini DM, Lubeck DP, et al. Predicting recurrence after radical prostatectomy for patients with high risk prostate cancer. J Urol. 2003; 169:157-63.

49. Kupelian PA, Katcher J, Levin HS, et al. Stage T1-2 prostate cancer: a multivariate analysis of factors affecting biochemical and clinical failures after radical prostatectomy. Int J Radiat Oncol Biol Phys. 1997; 37:1043-52.

50. Sakr WA, Tefilli MV, Grignon DJ, et al: Gleason score 7 prostate cancer: A heterogeneous entity? Correlation with pathologic parameters and disease-free survival. Urology 2000; 56:730-734.

51. Chan TY, Partin AW, Walsh PC, et al: Prognostic significance of Gleason score $3+4$ versus Gleason score $4+3$ tumor at radical prostatectomy. Urology 2000; 56:823-827.

52. Lau WK, Blute ML, Bostwick DG, et al: Prognostic factors for survival of patients with pathological Gleason score 7 prostate cancer: Differences in outcome between primary Gleason grades 3 and 4. J Urol 2001; 166:1692-1697.

53. Wheeler TM, Dillioglugil O, Kattan MW, et al. Clinical and pathological significance of the level and extent of capsular invasion in clinical stage T1-2 prostate cancer. Hum Pathol 1998, 29:856-862.

54. San Francisco IF, Regan MM, Olumi AF, et al. Percent of cores positive for cancer is a better preoperative predictor of cancer recurrence after radical prostatectomy than prostate specific antigen. J Urol. 2004; 171:1492-9.

55. Stamey TA, Yemoto CM, McNeal JE, et al. Prostate cancer is highly predictable: a prognostic equation based on all morphological variables in radical prostatectomy specimens. J Urol. 2000; 163:1155-60.

56. D'Amico AV, Chen MH, Roehl KA, et al. Preoperative PSA velocity and the risk of death from prostate cancer after radical prostatectomy. N Engl J Med 2004, 351:125-35.

57. Freedland SJ, Dorey F, Aronson WJ. Preoperative PSA velocity and doubling time do not predict adverse pathologic features or biochemical recurrence after radical prostatectomy. Urology 2001;57:476-80.

58. Loeb S, Kan D, Yu X, et al. Preoperative prostate specific antigen doubling time is not a useful predictor of biochemical progression after radical prostatectomy. J Urol. 2010; 183:1816-21.

59. Gonzalez CM, Roehl KA, Antenor JV, et al. Preoperative PSA level significantly associated with interval to biochemical progression after radical retropubic prostatectomy. Urology. 2004; 64:723-8.

60. Partin AW, Yoo J, Carter HB, et al. The use of prostate specific antigen, clinical stage and Gleason score to predict pathological stage in men with localized prostate cancer. J Urol. 1993; 150:110-4.

61. Epstein JI. Pathologic assessment of the surgical specimen. Urol Clin North Am. 2001; 28:567-94.

62. Theiss M, Wirth MP, Manseck A, et al. Prognostic significance of capsular invasion and capsular penetration in patients with clinically localized prostate cancer undergoing radical prostatectomy. Prostate 1995, 27:13-17.

63. Paulson DF. Impact of radical prostatectomy in the management of clinically localized disease. J Urol. 1994; 152(5 Pt 2):1826-30.

64. Pfitzenmaier J, Pahernik S, Tremmel T et al: Positive surgical margins after radical prostatectomy: do they have an impact on biochemical or clinical progression? BJU Int 2008; 102: 1413.

65. Cheng L, Darson MF, Bergstralh EJ, et al. Correlation of margin status and extraprostatic extension with progression of prostate carcinoma. Cancer 1999; 86: 1775- 82.

66. Simon MA, Kim S, Soloway MS. Prostate specific antigen recurrence rates are low after radical retropubic prostatectomy and positive margins. J Urol. 2006; 175:140-4.

67. Pettus JA, Weight CJ, Thompson CJ, et al. Biochemical failure in men following radical retropubic prostatectomy: impact of surgical margin status and location. J Urol. 2004; 172:129-32.

68. Vis AN, Roemeling S, Kranse R, et al. Should we replace the Gleason score with the amount of high-grade prostate cancer? Eur Urol. 2007; 51:931-9.

69. Jayachandran J, Bañez LL, Levy DE, et al. SEARCH Database Study Group. Risk stratification for biochemical recurrence in men with positive surgical margins or extracapsular disease after radical prostatectomy: results from the SEARCH database. J Urol. 2008; 179:1791-6.

70. Mann MJ, DeCastro GJ, Desai M, et al. Predictive significance of surgical margin status after prostatectomy for prostate cancer during PSA era. Urology. 2008; 72:1203-7.

71. Kupelian P, Katcher J, Levin H, et al. Correlation of clinical and pathologic factors with rising prostate-specific antigen profiles 
after radical prostatectomy alone for clinically localized prostate cancer. Urology 1996; 48: 249- 60.

72. Quinn DI, Henshall SM, Brenner PC, et al: Prognostic significance of preoperative factors in localized prostate carcinoma treated with radical prostatectomy: importance of percentage of biopsies that contain tumor and the presence of biopsy perineural invasion. Cancer 2003; 97: 1884-1893.

73. D'Amico AV, Whittington R, Malkowicz SB, et al. Prostate specific antigen outcome based on the extent of extracapsular extension and margin status in patients with seminal vesicle negative prostate carcinoma of Gleason score $<$ or $=7$. Cancer 2000; 88:2110- 5 .

74. van den Ouden D., Bentvelsen FM., Boeve ER, et al. Positive margins after radical prostatectomy: correlation with local recurrence and distant progression. Brit. J Urol. 1993; 72: 489-94.

75. Alkhateeb S, Alibhai S, Fleshner N, et al. Impact of positive surgical margins after radical prostatectomy differs by disease risk group. J Urol. 2010;183:145-50.

76. Epstein JI, Carmichael MJ, Pizov G, et al. Influence of capsular penetration on progression following radical prostatectomy: a study of 196 cases with long-term followup. J Urol 1993, 150:135-141.

77. Lowe BA, and Lieberman SF, Disease recurrence and progression in untreated pathologic stage T3 prostate cancer: selecting the patient for adjuvant therapy. J Urol 1997;158: 1452-1456.

78. Obek C, Sadek S, Lai S, et al. Positive surgical margins with radical retropubic prostatectomy: anatomic site-specific pathologic analysis and impact on prognosis. Urology. 1999; 54:682-8.

79. Freedland SJ, Presti JC, Kane CJ, et al. Do younger men have better biochemical outcomes after radical prostatectomy? Urology 2004, 63(3):518-22.

80. Smith CV, Bauer JJ, Connelly RR, et al: Prostate cancer in men age 50 years or younger: a review of the Department of Defense Center for Prostate Disease Research multicenter prostate cancer database. J Urol 2000; 164: 1964-1967.

81. Khan MA, Han M, Partin AW, et al. Long-term cancer control of radical prostatectomy in men younger than 50 years of age: update 2003. Urology 2003; 62: 86-91.

82. Siddiqui SA, Sengupta S, Slezak JM, et al. Impact of patient age at treatment on outcome following radical retropubic prostatectomy for prostate cancer. J Urol 2006; 175: 952-7.

83. Magheli A, Rais-Bahrami S, Humphreys EB, et al. Impact of patient age on biochemical recurrence rates following radical prostatectomy. J Urol. 2007; 178:1933-7.

84. Gretzer MB, Epstein JI, Pound CR, et al. Substratification of stage T1C prostate cancer based on the probability of biochemical recurrence. Urology. 2002; 60:1034-9

85. Amling CL, Riffengurgh RH, Sun L, et al. Pathologic variables and recurrence rates as related to obesity in men with prostate cancer undergoing radical prostatectomy. J Clin Oncol 2004; 22: 439-45.

86. Eastham JA, and Kattan MW: Disease recurrence in black and white men undergoing radical prostatectomy for clinical stage T1-T2 prostate cancer. J Urol 2000; 163: 143-145.

87. Fowler JE, and Terrell F: Survival in blacks and whites after treatment for localized prostate cancer. J Urol 1996; 156: 133-136.

88. Iselin CE, Box JW, Vollmer RT, et al: Surgical control of clinically localized prostate carcinoma is equivalent in African-American and white males. Cancer 1998; 83: 2353-2360.

89. Endrizzi J, Seay T: The relationship between early biochemical failure and perineural invasion in pathological T2 prostate cancer. Br J Urol 2000; 85:696.

90. Epstein JI. The role of perineural invasion and other bio -characteristics as prognostic markers for localized prostate cancer. Sem Urol Oncol. 1998; 16:124.
91. de la Taille A, Rubin MA, Bagiella E, et al. Can perineural invasion on prostate needle biopsy predict prostate specific antigen recurrence after radical prostatectomy? J Urol. 1999; 162:103-6.

92. Grignon DJ, Sakr WA. Pathologic staging of prostate carcinoma. What are the issues? Cancer 1996; 78:337-40.

93. Epstein JI, Carmichael M, Partin AW, et al. Is tumor volume an independent predictor of progression following radical prostatectomy? A multivariate analysis of 185 clinical stage B adenocarcinomas of the prostate with 5 years of followup. J Urol. 1993; 149:1478-8.

94. Kikuchi E, Scardino PT, Wheeler TM, et al. Is tumour volume an independent prognostic factor in clinically localized prostate cancer? J Urol 2004, 172:508-11.

95. Ramos CG, Roehl KA, Antenor JA, et al. Percent carcinoma in prostatectomy specimen is associated with risk of recurrence after radical prostatectomy in patients with pathologically organ confined prostate cancer. J Urol. 2004; 172:137-40.

96. Freedland SJ, Wieder JA, Jack GS, et al. Improved risk stratification for biochemical recurrence after radical prostatectomy using a novel risk group system based on prostate specific antigen density and biopsy Gleason score. J Urol. 2002; 168:110-5.

97. Schroeck FR, Kattan MW, Moul JW, et al. Re-calibration and external validation of an existing nomogram to predict aggressive recurrences after radical prostatectomy. BJU Int 2009; [Epub ahead of print]

98. Freedland SJ, Csathy GS, Frederick D, et al: Percent prostate needle biopsy tissue with cancer is more predictive of biochemical failure or adverse pathology after radical prostatectomy than prostate specific antigen or Gleason score. J Urol 2002; 167: 516-520.

99. Cupp MR, Bostwick PG, Myers RP, et al. The volume of prostate cancer in the biopsy specimen cannot reliably predict the quantity of cancer in the radical prostatectomy specimen on an individual basis. J Urol 1995; 153: 1543-8.

100.Freedland SJ, Aronson WJ, Terris MK, et al. The percentage of prostate needle biopsy cores with carcinoma from the more involved side of the biopsy as a predictor of prostate specific antigen recurrence after radical prostatectomy: results from the Shared Equal Access Regional Cancer Hospital (SEARCH) database. Cancer. 2003; 98:2344-50.

101.Linson PW, Lee AK, Doytchinova T, et al. Percentage of core lengths involved with prostate cancer: does it add to the percentage of positive prostate biopsies in predicting postoperative prostate-specific antigen outcome for men with intermediate-risk prostate cancer? Urology. 2002; 59:704-8.

102.Grossfeld GD, Latini DM, Lubeck DP, et al. Predicting disease recurrence in intermediate and high-risk patients undergoing radical prostatectomy using percent positive biopsies: results from CaPSURE. Urology. 2002; 59: 560-5.

103.Presti JC Jr, Shinohara K, Bacchetti P, et al. Positive fraction of systematic biopsies predicts risk of relapse after radical prostatectomy. Urology. 1998; 52:1079-84.

104.Bostwick DG, Grignon DJ, Hammond ME, et al. Prognostic factors in prostate cancer. College of American Pathologists Consensus Statement 1999. Arch Pathol Lab Med. 2000; 124:995-1000.

105.Strohmeyer D, Rossing C, Strauss F, et al.: Tumour angiogenesis is associated with progression after radical prostatectomy in pT2/pT3 prostate cancer. Prostate 2000, 42:26-33.

106.van den Ouden D, Hop WC, Kranse R, et al. Tumour control according to pathological variables in patients treated by radical prostatectomy for clinically localized carcinoma of the prostate. Br J Urol. 1997; 79:203-11.

107.Silberman MA, Partin AW, Veltri RW, et al: Tumor angiogenesis correlates with progression after radical prostatectomy but 
not with pathologic stage in Gleason sum 5 to 7 adenocarcinoma of the prostate. Cancer 1997; 79: 772-779.

108.Rubin MA, Buyyounouski M, Bagiella E, et al.: Microvessel density in prostate cancer: lack of correlation with tumour grade, pathologic stage, and clinical outcome. Urology 1999, 53:542-547.

109.Gettman MT, Pacelli A, Slezak J, et al.: Role of microvessel density in predicting recurrence in pathologic Stage T3 prostatic adenocarcinoma. Urology 1999, 54:479-485.

110. Bettencourt MC, Bauer JJ, Sesterhenn A, et al. CD34 immunohistochemical assessment of angiogenesis as a prognostic marker for prostate cancer recurrence after radical prostatectomy. J Urol 1998; 160:459-465.

111.Gettman MT, Bergstralh EJ, Blute M, et al: Prediction of patient outcome in pathologic stage T2 adenocarcinoma of the prostate: lack of significance for microvessel density analysis. Urology 1998; 51: 79-85.

112.Lee SE, Currin SM, Paulson DF, et al. Flow cytometric determination of ploidy in prostatic adenocarcinoma: a comparison with seminal vesicle involvement and histopathological grading as a predictor of clinical recurrence. J Urol. 1988; 140:769-74.

113.Montgomery BT, Nativ O, Blute ML, et al. Stage B prostate adenocarcinoma. Flow cytometric nuclear DNA ploidy analysis. Arch Surg. 1990; 125:327-31.

114.Nativ O, Winkler HZ, Raz Y, et al. Stage C prostatic adenocarcinoma: flow cytometric nuclear DNA ploidy analysis. Mayo Clin Proc. 1989; 64:911-9.

115. Hawkins CA, Bergstralh EJ, Lieber MM, et al. Influence of DNA ploidy and adjuvant treatment on progression and survival in patients with pathologic stage T3 (PT3) prostate cancer after radical retropubic prostatectomy. Urology. 1995; 46:356-64.

116.Carmichael MJ, Veltri RW, Partin AW, et al. Deoxyribonucleic acid ploidy analysis as a predictor of recurrence following radical prostatectomy for stage T2 disease. J Urol. 1995 ; 153(3 Pt 2):1015-9.

117. Halvorsen OJ, Hostmark J, Haukaas S, et al. Prognostic significance of p16 and CDK4 proteins in localized prostate carcinoma. Cancer 2000, 88: 416-424.

118.D'Amico, A. V., Whittington, R., Malkowicz, S. B., et al: Biochemical outcome after radical prostatectomy, external beam radiation therapy, or interstitial radiation therapy for clinically localized prostate cancer. JAMA 1998;280: 969- 74.

119.Stephenson AJ, Scardino PT, Eastham JA, et al. Postoperative nomogram predicting the 10-year probability of prostate cancer recurrence after radical prostatectomy. J Clin Oncol. 2005; 23:7005-12.

120.Kattan MW, Vickers AJ, Yu C, et al. Preoperative and postoperative nomograms incorporating surgeon experience for clinically localized prostate cancer. Cancer. 2009;115:1005-10.

121.Kattan MW, Wheeler TM, Scardino PT. Postoperative nomogram for disease recurrence after radical prostatectomy for prostate cancer. J Clin Oncol. 1999; 17:1499-507

122.Walz J, Chun FK, Klein EA, et al. Nomogram predicting the probability of early recurrence after radical prostatectomy for prostate cancer. J Urol. 2009; 181:601-7.

123. Moinpour CM, Hayden KA, Unger JM, et al. Health related quality of life results in pathologic stage $C$ prostate cancer from a Southwest Oncology Group trial comparing radical prostatectomy alone with radical prostatectomy plus radiation therapy. J Clin Oncol 2008; 26: 112. 